\title{
Photopharmacological control of bipolar cells restores visual function in blind mice
}

\author{
Laura Laprell, ${ }^{1,2}$ Ivan Tochitsky, ${ }^{3}$ Kuldeep Kaur, ${ }^{2}$ Michael B. Manookin, ${ }^{2}$ Marco Stein, ${ }^{1}$ David M. Barber, ${ }^{1}$ Christian Schön, ${ }^{4}$ \\ Stylianos Michalakis, ${ }^{4}$ Martin Biel, ${ }^{4}$ Richard H. Kramer, ${ }^{3}$ Martin P. Sumser, ${ }^{1}$ Dirk Trauner, ${ }^{1}$ and Russell N. Van Gelder ${ }^{2,5}$
}

${ }^{1}$ Center for Integrated Protein Science Munich and Department of Chemistry, Ludwig-Maximilians-Universität München, Munich, Cermany. ${ }^{2}$ Department of Ophthalmology, University of Washington School of Medicine, Seattle, Washington, USA. ${ }^{3}$ Department of Molecular and Cell Biology, University of California, Berkeley, Berkeley, California, USA. ${ }^{4}$ Center for Integrated Protein Science Munich and Department of Pharmacy, Center for Drug Research, Ludwig-Maximilians-Universität München, Munich, Germany. ${ }^{5}$ Department of Biological Structure and Department of Pathology, University of Washington School of Medicine, Seattle, Washington, USA.

\begin{abstract}
Photopharmacological control of neuronal activity using synthetic photochromic ligands, or photoswitches, is a promising approach for restoring visual function in patients suffering from degenerative retinal diseases. Azobenzene photoswitches, such as $A A Q$ and DENAQ, have been shown to restore the responses of retinal ganglion cells to light in mouse models of retinal degeneration but do not recapitulate native retinal signal processing. Here, we describe diethylamino-azodiethylamino (DAD), a third-generation photoswitch that is capable of restoring retinal ganglion cell light responses to blue or white light. In acute brain slices of murine layer $2 / 3$ cortical neurons, we determined that the photoswitch quickly relaxes to its inactive form in the dark. DAD is not permanently charged, and the uncharged form enables the photoswitch to rapidly and effectively cross biological barriers and thereby access and photosensitize retinal neurons. Intravitreal injection of DAD restored retinal light responses and light-driven behavior to blind mice. Unlike DENAQ, DAD acts upstream of retinal ganglion cells, primarily conferring light sensitivity to bipolar cells. Moreover, DAD was capable of generating ON and OFF visual responses in the blind retina by utilizing intrinsic retinal circuitry, which may be advantageous for restoring visual function.
\end{abstract}

\section{Introduction}

Degenerative diseases that affect the outer retina, such as retinitis pigmentosa or age-related macular degeneration, result in visual impairment and blindness. These diseases are characterized by the slow degeneration of rod and cone photoreceptors, followed by the remodeling of the remaining retinal circuitry $(1,2)$. Several approaches to restore visual function to blind patients with retinitis pigmentosa are currently under investigation. First, photoelectronic retinal prostheses can be implanted into the eye to electrically stimulate the surviving retinal neurons (3-5). The Argus II retinal implant has recently been approved by the US Food and Drug Administration as a treatment for retinitis pigmentosa, and the Alpha IMS (Retina Implant AG) was awarded a CE Mark in July 2013. Second, transplantation of stem cells or stem cell-derived cells is a promising approach to slowing or reversing retinal degeneration (6-11). Third, viral delivery and expression of optogenetic proteins (e.g., channelrhodopsin or LiGluR) targeted to specific retinal cell types can confer light sensitivity to the blind retina (12-14).

These approaches all have the potential to restore visual function, but each has specific limitations. Retinal implants are highly invasive and difficult to remove and replace. The potential acuity of implant-restored vision is limited by the relatively low density of stimulating electrodes, which is constrained by the safe levels of stimulat-

Conflict of interest: The authors have declared that no conflict of interest exists. Submitted: December 12, 2016; Accepted: April 18, 2017

Reference information: / Clin Invest. 2017;127(7):2598-2611.

https://doi.org/10.1172/JCI92156. ing electrical current. Stem cell treatments are irreversible and difficult to control precisely, while the expression of optogenetic tools requires viral gene therapy, which carries its own potential safety risks. The introduction of genetically engineered ion channels, such as LiGluR, also requires gene therapy, but the photoswitchable tethered ligands can at least be replaced by improved compounds, providing for potential flexibility for future innovation $(13,14)$.

Here, we describe an improved photopharmacological approach for restoring visual function using a photochromic ligand (PCL) that may circumvent these limitations. PCLs are light-sensitive small molecules, such as ion channel blockers $(15,16)$. These photoswitches can exist in two different configurations, i.e., (a) in their dark-adapted, thermodynamically stable trans-configuration or (b) in their less stable cis-configuration. Upon optical stimulation, PCLs reversibly switch between these two configurations, thereby altering the compounds' binding affinity for their target ion channels and, ultimately, enabling light-dependent control of neuronal function (15-17). Due to the simplicity of this pharmacological approach, PCLs can be added, removed, or improved as needed and do not require any permanent genetic or anatomic modification.

Recently, we demonstrated that photoswitchable voltage-gated ion channel (VGIC) blockers, such as AAQ and DENAQ, can restore light sensitivity in blind mice $(18,19)$. Very recently, we have shown that this approach can be extended to photochromic neurotransmitters (20). Here, we introduce a type of ion channel blocker, termed DAD (diethylamino-azo-diethylamino), which exhibits features we believe to be unique compared with the previously published PCLs 
A
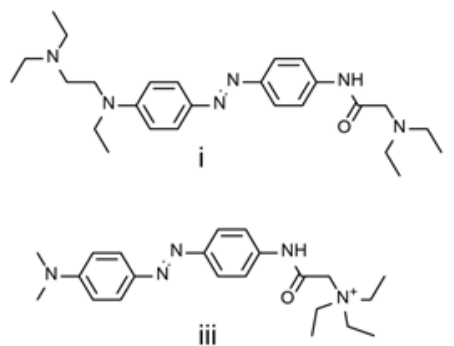

B
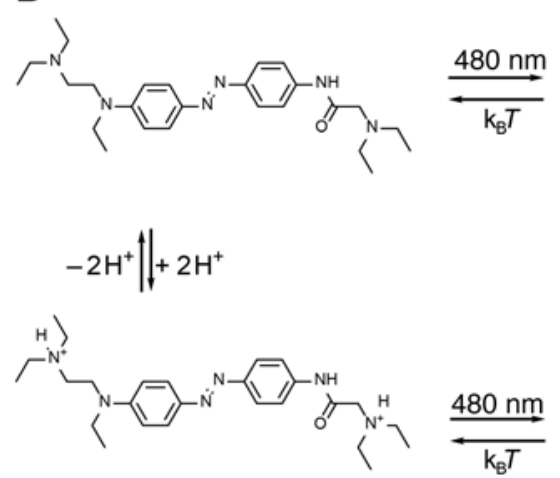

C

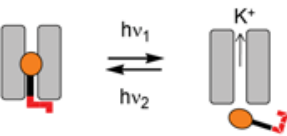

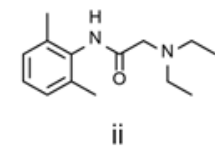

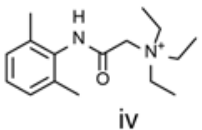

iv

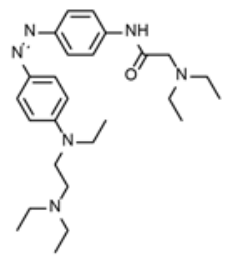

$-2 \mathrm{H}^{+} \mid+2 \mathrm{H}^{+}$

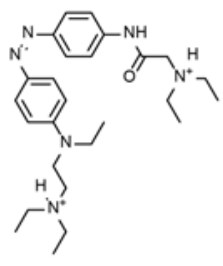

(Figure 1). We therefore consider this the first third-generation PCL in the VGIC family. DAD is not permanently charged, resulting in increased solubility and enhanced permeation. Furthermore, DAD selectively photosensitizes retinal neurons upstream of retinal ganglion cells (RGCs), which may enable more complex retinal signal processing. To demonstrate its potential for restoring visual function, we characterize the effect of DAD on the blind retina in vitro as well as in vivo.

\section{Results}

Synthesis, design, and logic of DAD. DAD (Figure 1, A and B) was designed as a bis-tertiary-amine, which enables it to cross biological barriers in the uncharged form while being highly soluble in physiological solution when singly or doubly charged. As such, it structurally resembles lidocaine (Figure 1A) and therefore may have a similar pharmacokinetic and pharmacodynamic profile. The relationship of DAD to its permanently charged secondgeneration analog DENAQ (Figure 1A) is similar to that of lidocaine and QX-314 (Figure 1A).

The synthesis of DAD is described in detail in the Supplemental Methods. DAD was prepared in 5 synthetic steps starting from the commercially available dye Disperse Red 1 (Sigma Aldrich). Key transformations included an Appel reaction, amide bond formation, and two nucleophilic substitution reactions using diethylamine. DAD possesses the typical UV-Vis absorption spectrum and thermal stability of a red-shifted azobenzene (Supplemental Figure 1A; supplemental material available online with this article; https://doi.org/10.1172/JCI92156DS1). It can be isomerized maximally to its cis form with 480-nm light and thermally relaxes

Figure 1. DAD is an uncharged photoswitch that responds to visible light. (A) Molecular structures of DAD (i), lidocaine (ii), DENAQ (iii), and QX-314 (iv). (B) DAD can exist in deprotonated or protonated forms. The uncharged state should be plasma-membrane permeable, enabling efficient loading into retinal neurons. Irradiation with blue or white light converts DAD to its less stable cis isomer, which quickly relaxes back to trans in darkness. (C) Schematic view of DAD's blocking mechanism.

back to trans with $\tau=33 \mathrm{~ms}$ in DMSO (mono-exponential fit of the decay, red line Supplemental Figure 1B).

Characterization of DAD in acute mouse brain slices. Previously published photoswitchable channel blockers affect various ion channels with different degrees of selectivity. Due to their rather nonspecific pharmacophore, i.e., the tetraethylamine moiety (TEA), many photoswitches target voltage-gated $\mathrm{K}^{+}\left(\mathrm{K}_{\mathrm{v}}\right)$ channels (21). As a proof of concept, we first assessed the effect of DAD on the function of layer $2 / 3$ cortical neurons, which express $\mathrm{K}_{v}$ and $\mathrm{Na}_{\mathrm{v}}$ channels. We determined DAD's wavelength sensitivity and kinetics in acute coronal brain slices from WT mice (Figure 2, A, B, and E). The optimal switching wavelengths were in the visible range between 400 and $480 \mathrm{~nm}$ (Figure 2, A and B), which is in accordance with DAD's UV-Vis absorbance spectrum (Supplemental Figure 1). In the dark-adapted state, trans-DAD blocks voltage-gated potassium channels (Figure 2C), while 460-nm illumination leads to unblocking of potassium channels within approximately $25 \mathrm{~ms}\left(\tau_{\text {unblock }}=27 \pm 0.86 \mathrm{~ms}, n=11\right.$ cells $)$ ( $\tau_{\text {unblock }}$ indicates mono-exponential fit of Kv-mediated current increase after switching on light.) (Figure 2D). Thermal relaxation occurs within $200 \mathrm{~ms}\left(\tau_{\text {off }}=201 \pm 12.1 \mathrm{~ms}\right)$ ( $\tau_{\text {off }}$ indicates monoexponential fit of $\mathrm{Kv}$-mediated current decrease after switching on light), but $\tau_{\text {off }}$ can be significantly decreased using 520 -nm light $\left(\tau_{\text {off }}=72.1 \pm 8.7 \mathrm{~ms}, P<0.001, n=9\right.$ cells) (Figure 2E). Only a minor effect of DAD could be detected when tested for sodium channel block by a voltage jump from membrane resting potential to a holding potential $0 \mathrm{mV}$ (peak sodium channel currents before application of DAD $\left[\mathrm{I}_{\text {peak Na }}\right]=-3.42 \pm 0.27 \mathrm{nA}$ and peak sodium channel currents after the application of DAD $\left[\mathrm{I}_{\text {peakNa-DAD }}\right]=-2.98 \pm 0.35 \mathrm{nA}$, $P=0.06, n=6$ ).

$D A D$ restores light responses in the retinas of blind mice ex vivo. We next investigated the ability of DAD to restore light sensitivity in blind retinas. We utilized retinas from 3- to 7-month-old blind triple-knockout (TKO) mice ( $\mathrm{Cnga3}^{-/-} \mathrm{Rho}^{-/-} \mathrm{Opn} 4^{-/-}$mice, which are deficient in cyclic nucleotide-gated channel $\alpha 3$, rhodopsin, and melanopsin), which lack all native light responses driven by photoreceptors or photosensitive RGCs. The double knockout of Cnga3 and Rho results in the loss of photoreceptors within the first 3 months after birth (22). Retinas were placed on a multielectrode array (MEA) to record light-dependent spiking activity from RGCs. For quantification of light-dependent spiking, we used the photoswitch index (PI), i.e., the normalized change in average firing rate upon illumination (18). A PI of $\mathrm{O}$ indicates no light-dependent changes in spiking frequency, whereas a positive or negative PI implies an increase or decrease in spiking frequency upon illumination, respectively. Before the application of DAD, 460-nm light had no effect on the RGC firing rate $(13.9 \pm 3.4$ spikes/s and $13.4 \pm 2.8$ spikes/s, respectively, average $\mathrm{PI}=-0.06 \pm 0.10, P=0.43 ; n=6$ retinas) (Figure $3, \mathrm{~A}$ and 
A
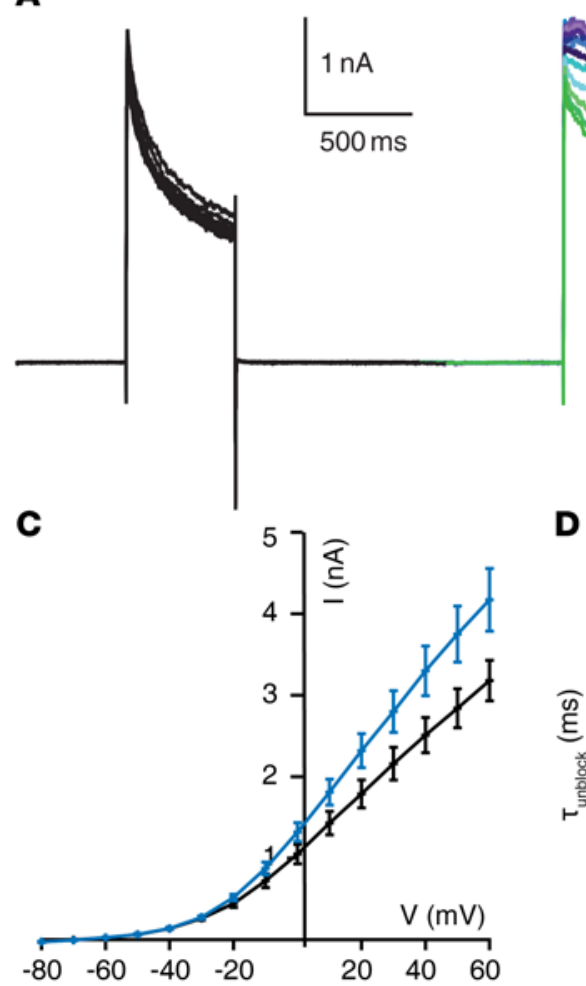
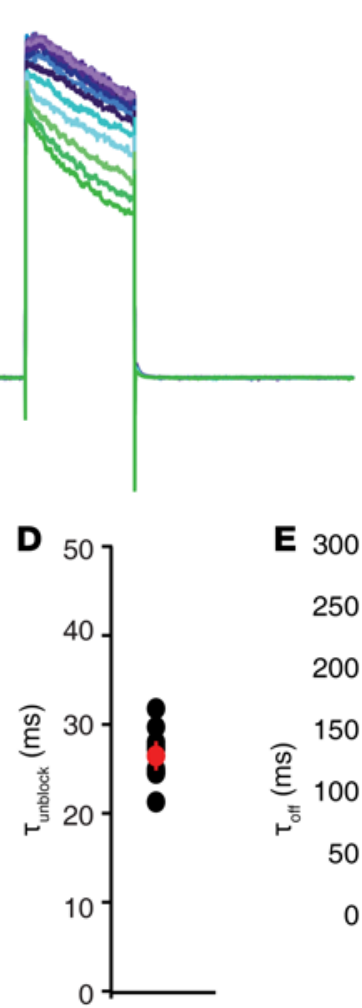
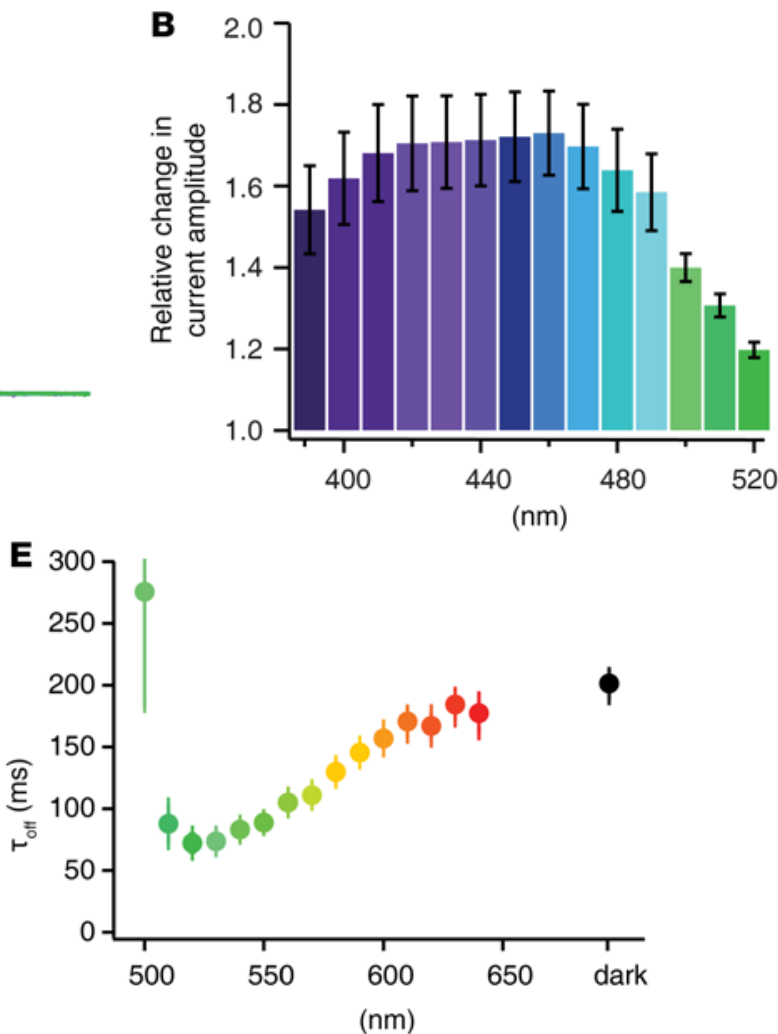

Figure 2. Characterization of DAD in layer $\mathbf{2} / \mathbf{3}$ cortical neurons in the visual cortex of an acute brain slice of WT mice. (A) Whole-cell recording after incubation with $200 \mu \mathrm{M}$ DAD in the presence of $1 \mu \mathrm{M}$ TTX. Potassium ( $\mathrm{K}_{v}$ ) outward currents were activated by a step from $-70 \mathrm{mV}$ to $+50 \mathrm{mV}$. Currents in darkness (left) compared with currents in the presence of light (right, $380 \mathrm{~nm}-520 \mathrm{~nm}$ ). (B) Normalized change in $\mathrm{K}_{\mathrm{v}}$ current in DAD-treated cortical neurons in response to stimulation with light of different wavelengths. (C) Current-voltage relationship in darkness (black) and under 460-nm light (blue). (D) Kinetics of unblocking the pore of $\mathrm{K}_{\mathrm{v}}$ channels at $+50 \mathrm{mV}$ holding potential, while switching between light and dark. $\tau_{\text {unblock }}=27 \pm 0.86 \mathrm{~ms}$ ( $n=11$ cells). (E) Quantification of OFF kinetics in response to different wavelength. Fastest OFF responses were achieved at $520-\mathrm{nm}$ light $\left(\tau_{\text {off }}=72.1 \pm 8.7 \mathrm{~ms}, n=9\right.$ cells $)$. DAD activity thermally switches off within $201 \pm 12.1 \mathrm{~ms}$ ( $n=8$ cells).

C). After a 3-minute incubation with $200 \mu \mathrm{M} \mathrm{DAD}$, light elicited a 2.6-fold increase in average RGC firing rate (RGC firing rate in the dark $=8.46 \pm 1.41$ spikes/s and in the light $22.02 \pm 2.78$ spikes/s, respectively; average PI $=0.42 \pm 0.05, P=0.0002$; $n=13$ retinas) (Figure $3, \mathrm{~B}$ and $\mathrm{D}$ ). The PI of DAD-treated TKO retinas was close to that of WT retinas (photoswitch index wild type $\left.\left[\mathrm{PI}_{\mathrm{ww}}\right]=0.65 \pm 0.05\right)(14)$, as was the PI distribution (Supplemental Figure 2). In addition, the application of DAD resulted in an average decrease of $4.3 \mathrm{~Hz}$ in spontaneous firing rate in darkness in DAD-treated TKO retinas, thereby increasing signal to noise $(18.01 \pm 1.58$ spikes/s and $13.69 \pm 1.90$ spikes/s, respectively; $n=10$ retinas, $P=0.0039$ ).

When analyzed on a single-cell level, photoswitch-activated RGCs can be classified by their light response polarity in cells that increase their firing rate upon illumination (66\% of all RGCs), those increasing their firing rate when light is turned off $(22 \%)$, and those responding both to light onset and offset (12\%) $(n=687$ RGCs in 11 retinas). Individual RGCs with a pronounced light OFF response were present in all MEA recordings. However, only a few retinas had a sufficiently high number of light OFF responses to be recognizable in the histogram (Supplemental Figure 3A). This was true not only for the blind TKO mouse line, but also for an alternative model for outer retinal degeneration, the $r d 1$ mouse line, which expresses a nonsense mutation in PDE6b (23) (Supplemental Figure 3B). In addition, correlation plots of individual experiments were performed (Supplemental Figure 3C) as well as cell-attached patch-clamp recordings on RGCs (Supplemental Figure 4). In these patch-clamp experiments, we not only verified the presence of light ON and OFF responses, but observed light responses with different kinetics. Those RGCs that responded to light with a fast transient light ON response were further investigated with higher-frequency stimulation (Supplemental Figure $4 \mathrm{~A}$, traces 1 and 2). A stimulation frequency of $5 \mathrm{~Hz}$ could be followed with a failure rate of $11.5 \% \pm 4.7 \%$ (i.e., the number of light stimuli with no spike in 100 sweeps) ( $n=4$ cells). After increasing the light stimulation frequency to $10 \mathrm{~Hz}$, the failure rate rose to $23.7 \% \pm 13.3 \%$ and the number of spikes per light stimulus decreased (Supplemental Figure 4, B and C). However, in some cases, even a $10-\mathrm{Hz}$ stimulus could be followed with a failure rate of 0\% (Supplemental Figure 4B).

$D A D$ preferentially photosensitizes bipolar cells. In order to evoke the observed, diverse pattern of RGC light responses, it is likely that DAD photosensitizes retinal neurons upstream of RGCs (i.e., bipolar and/or amacrine cells). We tested this hypothesis by synaptically isolating RGCs via application of $\mathrm{CdCl}_{2}$, which completely abolished the DAD-mediated light response (average 
A

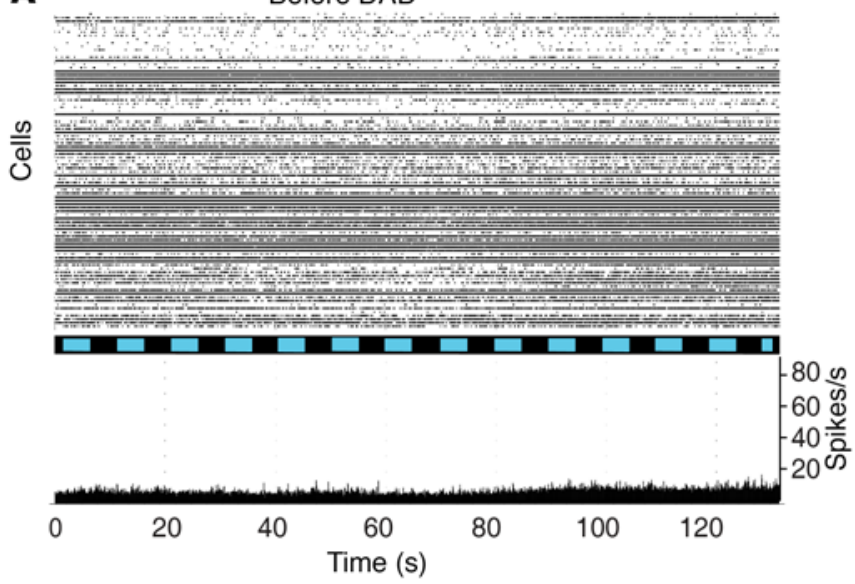

B

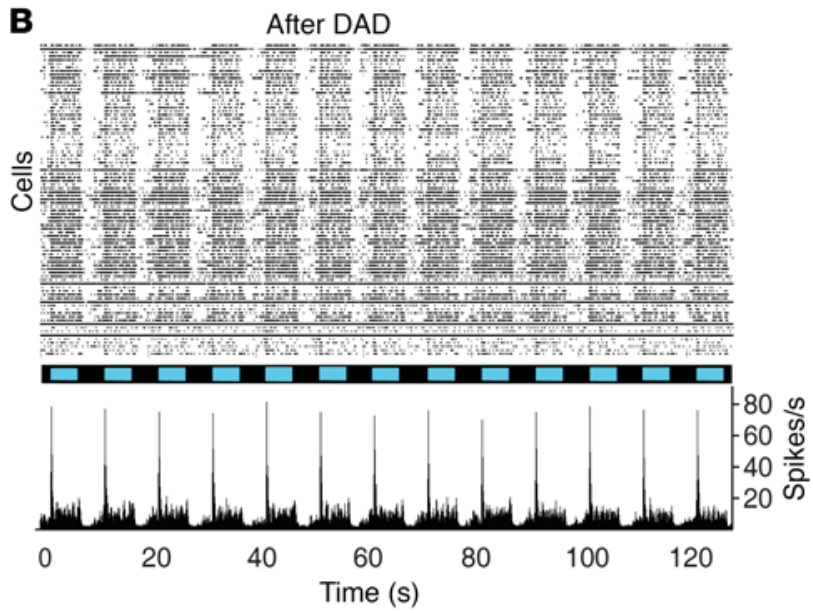

D

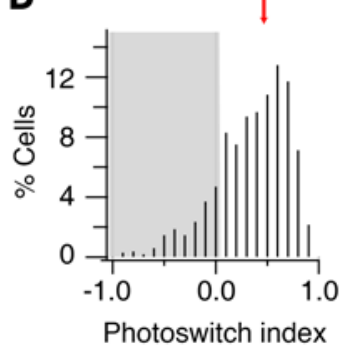

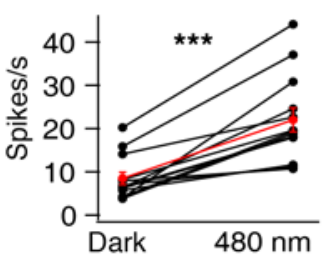

Figure 3. DAD restores light responses in blind TKO mice retinas. ( $\mathbf{A}$ and $\mathbf{B})$ Raster plot and histogram of $\mathrm{MEA}$ recordings in TKO retinas $(\mathbf{A})$ before $(\mathrm{PI}=-0.01)$ and (B) after treatment with $200 \mu \mathrm{M} \mathrm{DAD}(\mathrm{PI}=0.69$ ). The bar underneath the raster plot indicates light/dark stimulation (blue: $460 \mathrm{~nm}$; black: dark). (C and D) Light responses statistics for TKO retinas (C) before and (D) after DAD application. Distribution of PIs for RGC populations (before $n=300$ cells; after $n=1,024$ cells) is shown to the left. The red arrows indicate the mean PI of the RGC population. Average spiking rate in darkness and with $460-\mathrm{nm}$ light is shown to the right (before: $n=6$ retinas; after: $n=13$ retinas). Statistical analysis was performed using the signed Wilcoxon rank-sum test. ${ }^{* *} P<0.001$.

$\mathrm{PI}=-0.02 \pm 0.01, n=8$ retinas, $P<0.05)$ (Supplemental Figure $5 \mathrm{~A})$. The light response was also strongly reduced when excitatory synaptic transmission was selectively blocked using NBQX and D-AP5 (average PI $=0.08 \pm 0.01, n=6$ retinas) (Figure $4, \mathrm{~A}$ and B). Pharmacological blockade of inhibitory synaptic inputs did not eliminate the light response or invert its polarity $(\mathrm{PI}=0.32 \pm$ $0.03, n=6$ retinas) (Supplemental Figure 5B). Here, the overall reduction in PI results from an increase in basal activity, whereas the light response remains largely unaffected. This is in contrast to AAQ-mediated light responses, which inverted after blockade of inhibitory inputs (18). These results suggest that DAD mainly photosensitizes bipolar cells rather than amacrine cells or RGCs.

To confirm our hypothesis that DAD primarily photosensitizes bipolar cells and investigate whether the intrinsic retinal circuitry is utilized, we performed patch-clamp experiments on RGCs in retinal whole-mount preparations. Excitatory and inhibitory postsynaptic currents (EPSCs and IPSCs, respectively) were recorded using an intracellular solution blocking all intrinsic activity of the recorded RGC. Before treatment with DAD, RGC recordings showed no light-dependent postsynaptic potentials (average EPSC $=-2.97 \pm 0.77 \mathrm{pA}, n=9$ cells; average IPSC $=3.51 \pm 0.52 \mathrm{pA}$, $n=9$ cells) (Figure $4, \mathrm{C}, \mathrm{D}$, and G). In contrast, after the application of DAD, light-dependent EPSCs were observed in 94.1\% of RGCs and IPSCs were observed in $82.4 \%$ of RGCs (average EPSC $=-76.97 \pm 8.65 \mathrm{pA}, n=17$ cells, average IPSC $=135.24 \pm 41.73$ $\mathrm{pA}, n=16$ cells) (Figure 4, E and F, black traces and Figure 4G).
Notably, both EPSCs and IPSCs could be significantly reduced by application of NBQX and D-AP5 (average EPSC $=-10.87 \pm 5.47 \mathrm{pA}$, $n=11$ cells $P<0.001$; average IPSC $=7.03 \pm 3.79 \mathrm{pA}, n=13$ cells, $P=0.01$ ) (Figure $4, \mathrm{E}$ and $\mathrm{F}$, red traces and Figure $4 \mathrm{G}$ ). These findings demonstrate that DAD is capable of generating light-elicited excitatory and inhibitory synaptic inputs on RGCs, by photosensitizing bipolar cells, while DAD does not directly act on amacrine cells (Figure 4, E, F, and $\mathrm{H}$ ).

In an additional set of patch-clamp recording experiments on RGCs, DAD was applied either intracellularly or extracellularly to investigate whether the accessibility of DAD in RGCs plays a role in their photosensitization. When DAD was applied in the intracellular solution, small and slow light-induced currents were detected at a holding potential of $-75 \mathrm{mV}$ (Supplemental Figure $6 \mathrm{~A}$ ). These currents increased at $-100 \mathrm{mV}$ (Supplemental Figure 6, A and G). After extracellular DAD application, light-induced currents resembled the sole excitatory input from bipolar cells, which exhibited a large peak current followed by a smaller plateau phase (Supplemental Figure 6B). The fast component could be blocked by the application of NBQX and D-AP5, indicating that it originates from bipolar cells (Supplemental Figure 6C).

A larger light-induced current at $-100 \mathrm{mV}$ compared with -75 $\mathrm{mV}$ holding potential indicates an effect of DAD on HCN channels (Supplemental Figure 6). We therefore tested DAD in presence of $75 \mu \mathrm{M}$ ivabradine, a selective blocker of hyperpolarizationactivated currents $\left(\mathrm{I}_{\mathrm{h}}\right)$ currents on MEA (24). The application 


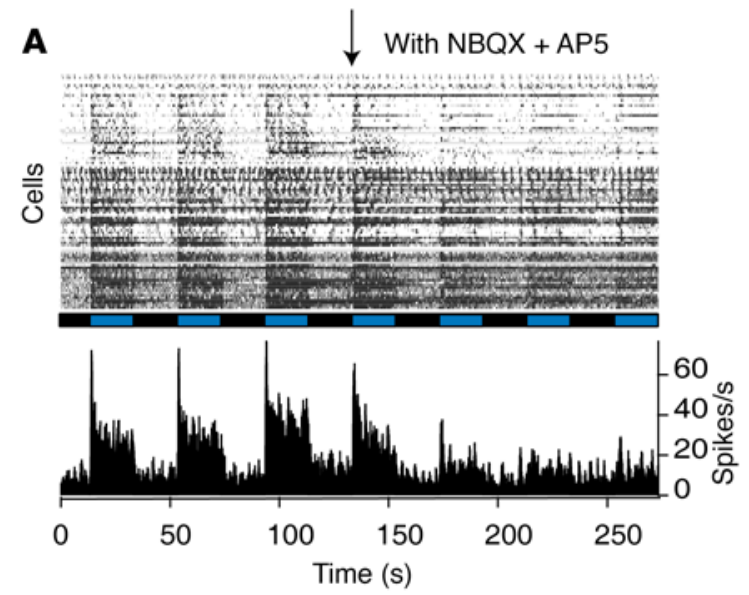

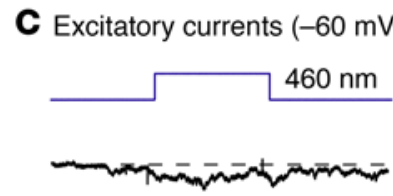

E Excitatory currents (-60 mV)

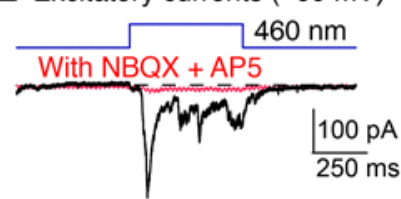

D Inhibitory currents $(0 \mathrm{mV})$

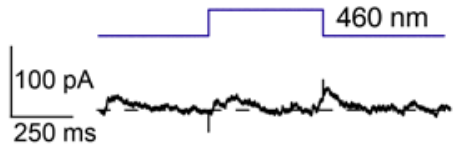

$\mathbf{F}$

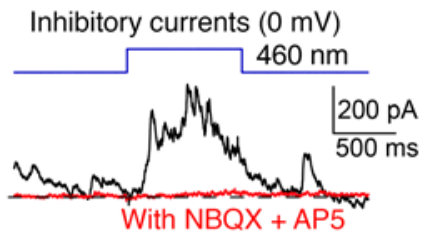

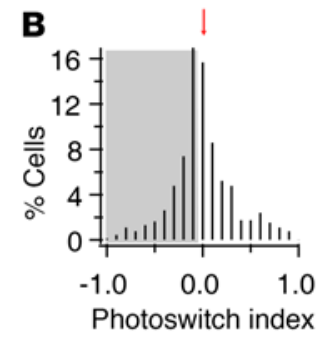

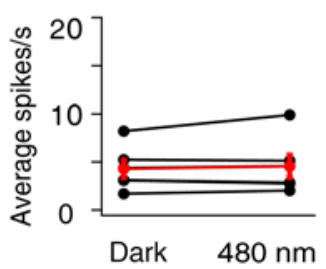

$480 \mathrm{~nm}$

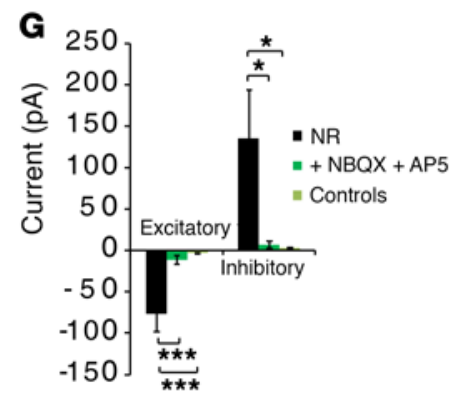

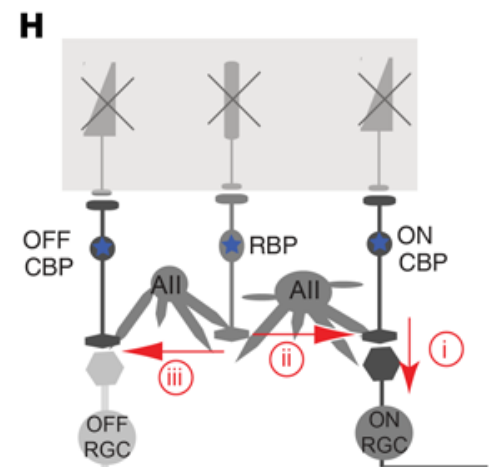

Figure 4. DAD selectively photosensitizes bipolar cells in TKO retinas. (A) Raster plot of an MEA recording from a DAD-treated TKO retina before and after wash in of $25 \mu \mathrm{M}$ NBQX and $50 \mu \mathrm{M}$ D-AP5. (B) Distribution of TKO RGC PI values after excitatory synaptic blockade is shown on the left (PI = 0.08 $\pm 0.01, n=477$ cells). Average RGC firing rate in darkness and under $460-\mathrm{nm}$ light is shown on the right ( $n=6$ retinas). (C) EPSC recording from a TKO RGC held at $-60 \mathrm{mV}$. Blue line indicates the light pulse. (D) IPSC recording in the same cell as in $\mathbf{C}$ held at $0 \mathrm{mV}$. (E and F) EPSC and IPSC recordings from a TKO RGC after DAD treatment (black trace). The red trace was recorded after excitatory synaptic blockade. (G) Quantification of EPSCs and IPSCs in DAD-treated TKO RGCs, before and after blockade of excitatory synaptic inputs (average EPSC $=-10.87 \pm 5.47 \mathrm{pA}, n=11$ cells, $P<0.001$; average IPSC $=7.03 \pm 3.79 \mathrm{pA}, n=13$ cells, $P=0.01)$. Statistical analysis was performed using the nonsigned Wilcoxon rank-sum test. ${ }^{*} P<0.05,{ }^{* * *} P<0.001$. (H) Overview of three possible DAD-mediated light response pathways. (i) Activated cone bipolar cells (CBP) directly transmit the signal onto RGCs. (ii) Activated rod bipolar cells (RBP) signal to All amacrine cells, which form synapses on CBP terminals. (iii) Off light responses are transmitted via RBP and All amacrine cells, which synapse on OFF RGCs (3).

of ivabradine resulted in an increase in background firing rate; however, it did not eliminate DAD-induced peak light responses (Supplemental Figure 7) (photoswitch index in presence of ivabradine $\left[\mathrm{PI}_{\mathrm{iva}}\right]=0.24 \pm 0.07, P=0.03, n=6$ retinas). This result was confirmed in patch-clamp experiments after application of DAD and ivabradine to the extracellular solution. At holding potentials of both $-75 \mathrm{mV}$ and $-100 \mathrm{mV}$, plateau currents were small whereas peak currents were unaffected by block of HCN channels (Supplemental Figure 8).

Previous generation photoswitches have been shown to target HCN channels as well (19), and recently, Tochitsky et al. demonstrated that the uptake of second-generation photoswitches relies on $\mathrm{P}_{2} \mathrm{X}$ receptor expression (25). We therefore assessed whether DAD uptake into retinal cells also depends on the expression and activation of $\mathrm{P}_{2} \mathrm{X}$ receptors in degenerated retinas. Application of $1 \mathrm{mM}$ PPADS prior to DAD administration, however, did not result in a decrease of light response but rather led to an improvement in the light response (Supplemental Figure 9, $\mathrm{PI}=0.52 \pm 0.05, n=4$ retinas).

$D A D$ application induces transient currents in bipolar cells. The results in RGC patch-clamp and MEA experiments in presence of ivabradine revealed that the transient peak current induced by DAD in bipolar cells is the pivotal light signal. We therefore performed patch experiments in bipolar cells directly. Bipolar cells and amacrine cells were discriminated by intracellular application of Lucifer Yellow (Figure 5, A and B, respectively). Bipolar cells were held at a membrane potential of $-54 \mathrm{mV}$, close to that reported as the membrane resting potential of $\mathrm{ON}$ bipolar cells in retinas of an $r d 1$ mouse model (26). Before the application of DAD, no light responses were detected, except an artifact induced by the LED (time to peak $0.15 \pm 0.008 \mathrm{~ms}$ ) (Figure $5 \mathrm{C}$ and Supplemental Figure $10, n=8)$. The application of $200 \mu \mathrm{M}$ DAD for 3 minutes led to a transient light response of $-65.19 \pm 6.34 \mathrm{pA}$ in ON and OFF bipolar cells, which is in a similar range to light-evoked responses of WT bipolar cells as well as metabotropic glutamatergic CPPG-mediated responses $(27,28)$. The time to peak was detected with $0.62 \pm 0.07 \mathrm{~ms}(n=8)$ (Figure 5D). Intracellular application of TEA, $\mathrm{Cs}^{+}$, and EGTA as well as extracellular application of TTX did not significantly affect current size or time to peak $(-54.83 \pm$ $6.49 \mathrm{pA}$ and $0.67 \pm 0.25 \mathrm{~ms}, P=0.37$ and $P=0.83$, respectively) (Supplemental Figure 11, A and B). To further confirm that this 
A

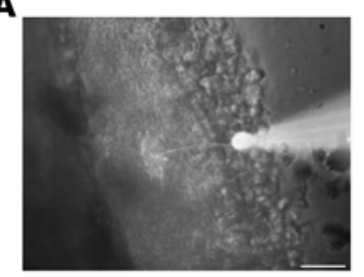

C

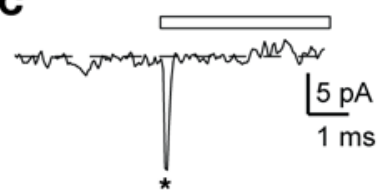

E

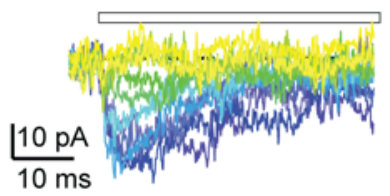

B

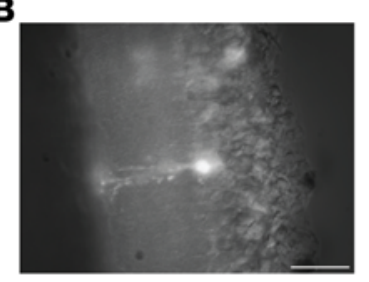

D

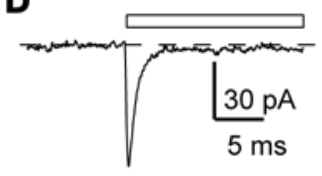

$\mathbf{F}$

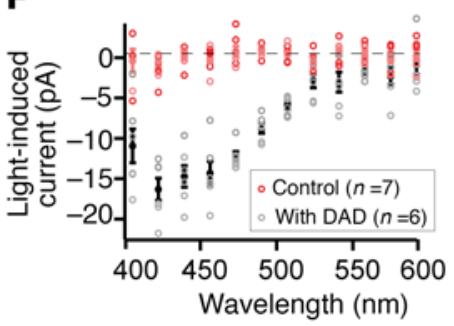

H
G
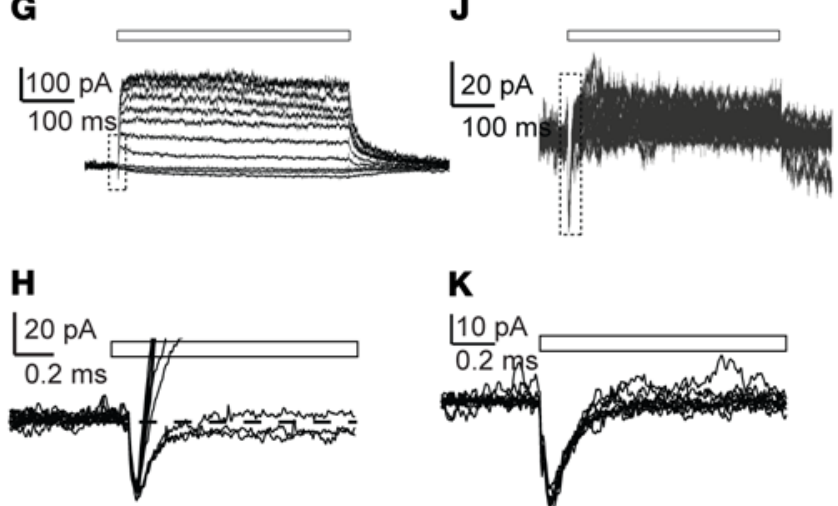

I

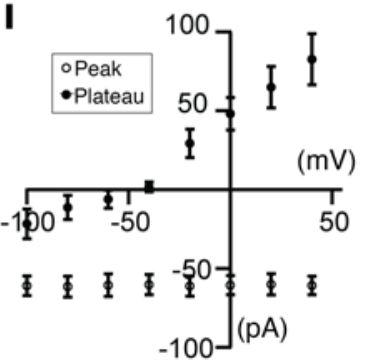

$\mathbf{K}$

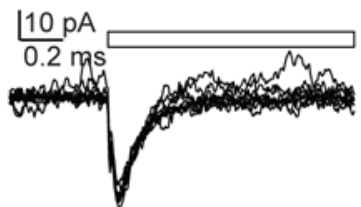

$\mathbf{L}$

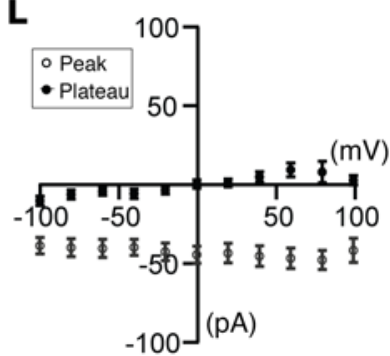

Figure 5. DAD induces transient currents in bipolar cells. (A) Fluorescence image of a bipolar cell filled with Lucifer Yellow after whole-cell patch-clamp configuration. Scale bar: $25 \mu \mathrm{m}$. (B) Fluorescence image of an amacrine cell filled with Lucifer Yellow after whole-cell patch-clamp configuration. Scale bar: $50 \mu \mathrm{m}$ (C) Voltage-clamp recording of a bipolar cell before application of DAD. Peristimulus time histogram (PTSH) of 5 sweeps. The asterisk marks a light artefact induced by the LED. The bar above the trace marks the light stimulation with $460-\mathrm{nm}$ light. (D) Voltage-clamp recording after the incubation with DAD. PSTH of 5 consecutive sweeps. (E) Raw data voltage-clamp recordings depending on the wavelength. (F) Analysis of wavelength screens in E. Red indicates wavelength screens before the application of DAD. Black indicates wavelength screenings after the application of DAD ( $n=7$ cells controls, $n=6$ cells after DAD application). (G-I) IV relationships of DAD-mediated currents in the absence of any blockers. (C) Raw data trace for voltages from -100 to $+40 \mathrm{mV}$. (H) Enlargement of box in Ga. (I) Analysis of IV relationships. Empty circles indicate transient peak current. Black circles indicate late $\mathrm{K}_{\mathrm{v}}$-channel component $(n=8)$. (J-L) Same experiments as in G-I, respectively, but in presence of TTX in the extracellular solution and TEA, Cs ${ }^{+}$, and EGTA in the intracellular solution $(n=8)$.

peak current is mediated by DAD, we performed a wavelength screen $(n=8$ cells $)$ and measured a similar wavelength sensitivity spectrum to that in response to DAD application in acute brain slice preparations (Figure 2 and Figure 5, E and F), which is also consistent with UV-Vis measurements (Supplemental Figure 1). These data are consistent with the conclusion that DAD mediates a transient excitatory (inward) current in retinal bipolar cells.

DAD was designed specifically to modulate with $\mathrm{K}^{+}$channels that exhibit voltage-dependent conductance (29). However, direct measurement of the DAD-evoked light response in whole-cell voltage clamp revealed that these currents were not, in fact, voltage dependent. Instead, DAD-evoked peak currents were inward at all holding potentials tested (-100 to $+40 \mathrm{mV}$; Figure 5 , G-L). After application of DAD, two light-dependent currents were detected: (a) a short transient light response, which was independent from membrane holding potential, and (b) a slow, sustained, outward-rectifying current. The transient component could not be blocked by the extracellular application of TTX and intracellular application of TEA, $\mathrm{Cs}^{+}$, and EGTA, whereas the slow-sustained current was sensitive to these blockers (Figure 5, G-L, respectively). Thus, the sustained, but not the transient, response was mediated by $\mathrm{K}_{v}$ channels in the bipolar cells. The mechanisms mediating the transient, non-voltage-dependent response are less clear. One possibility is that this transient response was mediated by responses arising from neighboring bipolar cells, which were conveyed through gap junctional coupling (30-32). Moreover, intracellular application of ion channel blockers would not affect neighboring cells and, therefore, the currents cannot be blocked completely. To determine whether disrupting bipolar cell coupling would reduce the transient DAD-elicited currents, we bath applied the gap junction blocker meclofenamic acid (MFA; 200 $\mu \mathrm{M})$ (33). Consistent with a gap junctional origin, application of MFA reduced the transient current response by more than $50 \%$ $(-25.07 \pm 4.51 \mathrm{pA})$ in bipolar cell patch experiments (Supplemental Figure 11, C and D) as well as in MEA recordings (Supplemental Figure 11, E-G).

DAD selectively photosensitizes retinas undergoing photoreceptor degeneration. Photoreceptor degeneration is accompanied by synaptic remodeling and neural reprogramming $(2,34)$. Retinal remodeling also causes changes in the expression of various receptors and ion channels and can facilitate the selective photosensitization of the blind retina by azobenzene photoswitches (19). To determine whether the effect of DAD is selective for the blind retina, we evaluated its ability to photosensitize retinas from WT mice and other blind mouse strains with and without retinal degeneration.

The analysis of DAD-mediated photosensitization was performed using 5 different mouse lines: 2 blind mouse lines undergoing retinal degeneration (TKO mice and PdeGbrldrdl $O p n 4^{-/-}$ 
A

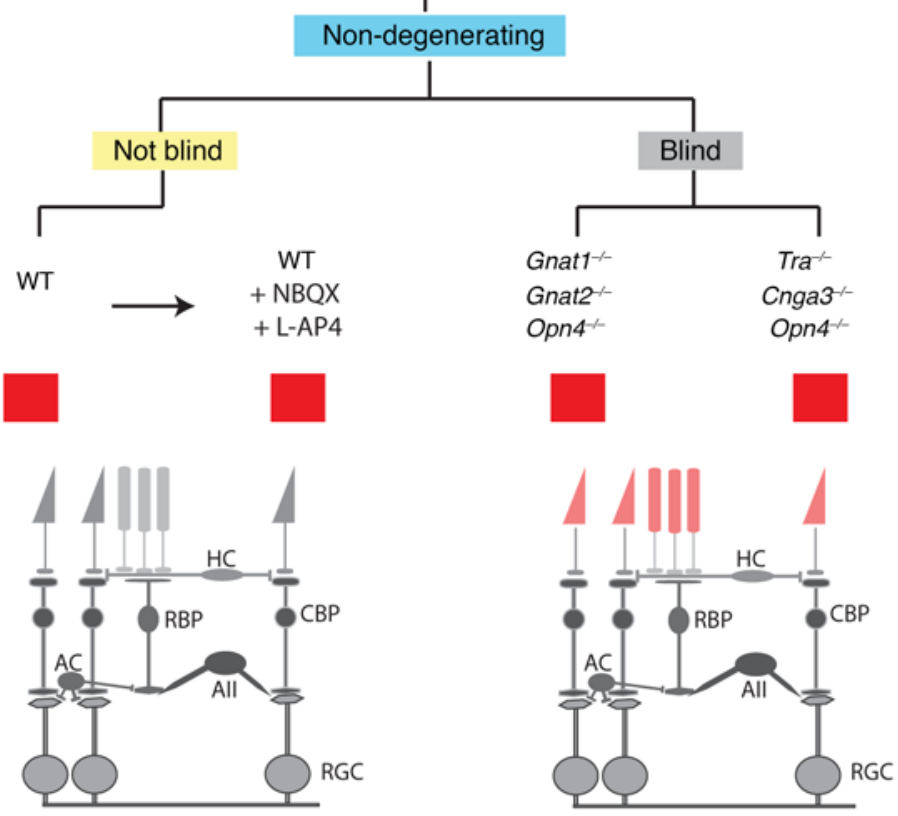

\section{Degenerating}
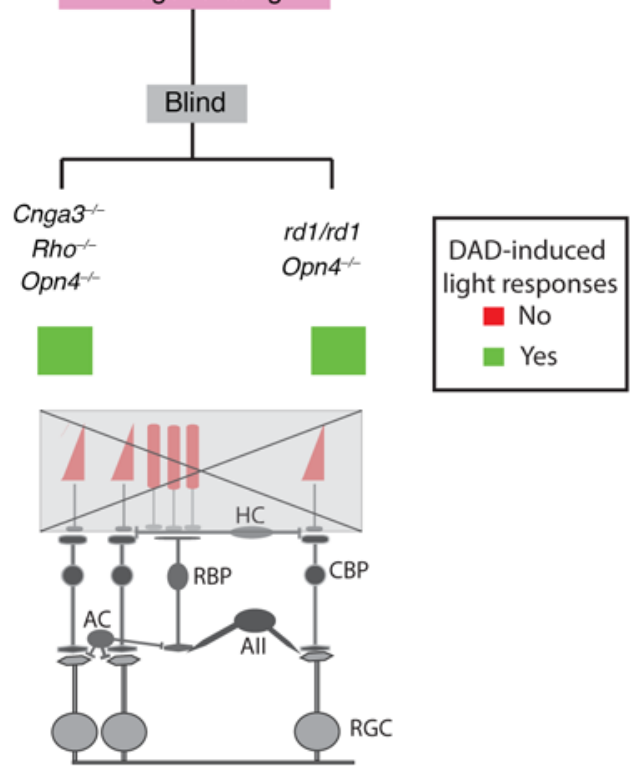

B

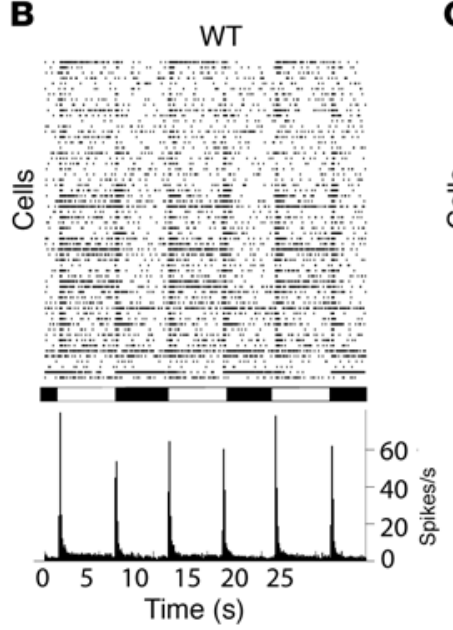

C

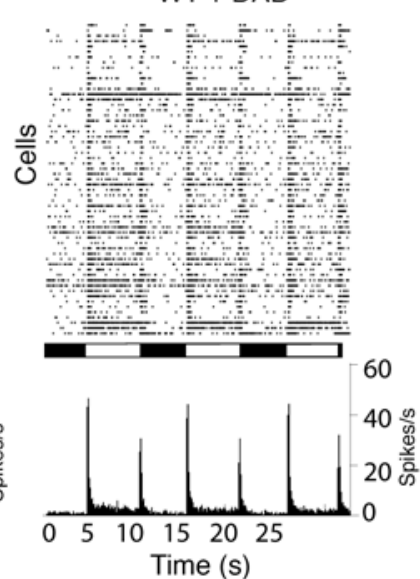

D
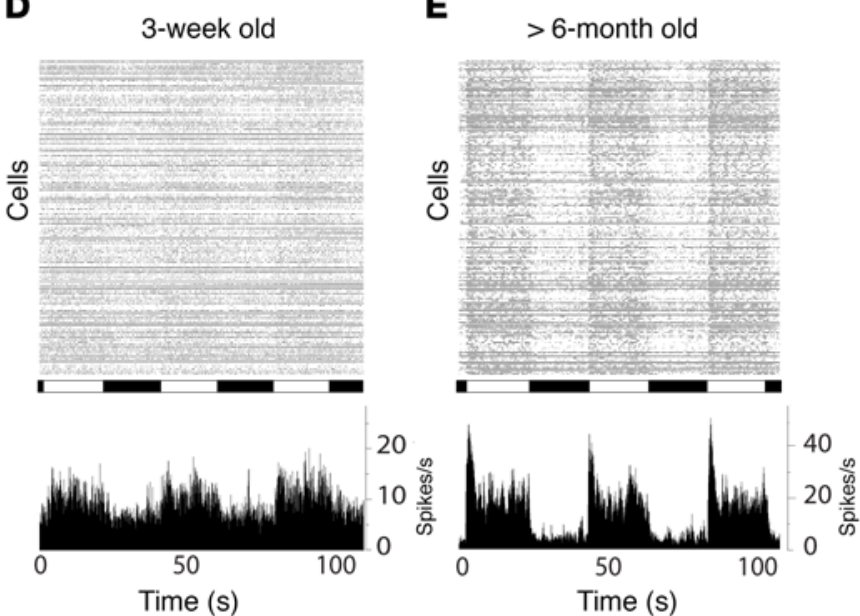

$\mathbf{E}$

E $\quad>6$-month old

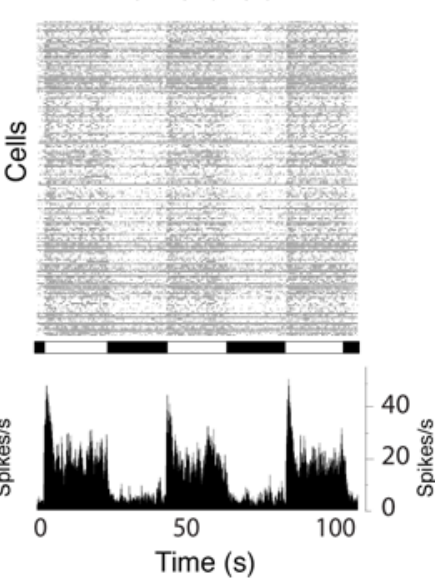

$\mathbf{F}$

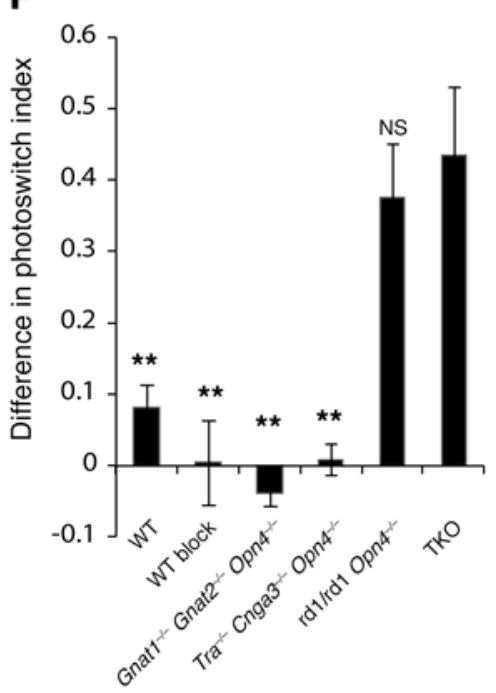

G

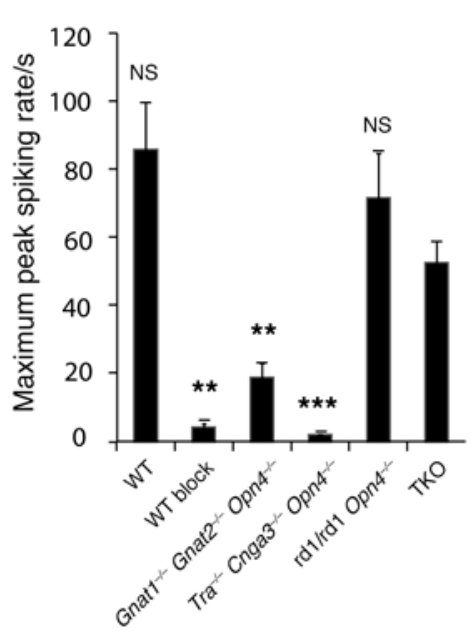

\section{H}

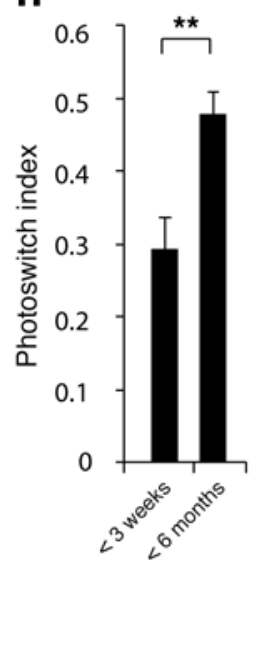


Figure 6. DAD selectively photosensitizes retinas undergoing photoreceptor degeneration. (A) Overview of mouse models tested for DAD-dependent restoration of light sensitivity. (B and C) MEA recording from WT retinas (B) before and (C) after DAD treatment. The bar underneath the raster plot indicates light/dark stimulation (white: white light; black: darkness). (D and E) MEA recording (D) from 3-week-old TKO retina after DAD application (PI = 0.34) and (E) from old retinas (>6 months) after DAD application (PI = 0.64). ( $\mathbf{F}$ and $\mathbf{G}$ ) Difference in $(\mathbf{F})$ mean $\mathrm{PI}$ and $(\mathbf{G})$ RGC firing rates before and after treatment

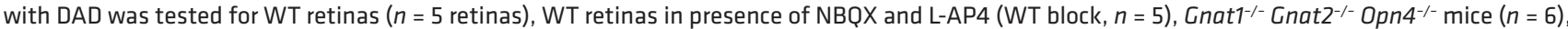
$\mathrm{Cnga3}^{-1-}$ Cnat1 $^{-1-} \mathrm{Opn4^{-/- }}$ mice $(n=5), r d 10 p n 4^{-1-}$ mice $(n=5)$, and TKO mice $(n=13)$. Statistical tests were performed in respect to change in TKO mice and Bonferroni corrected. (H) Photoswitch indices for DAD-treated TKO retinas in young ( $<3$ weeks, $n=7$ retinas) versus old mice ( $>6$ months, $n=6$ retinas). Statistical analysis was performed using the nonsigned Wilcoxon rank-sum test. ${ }^{* *} P<0.01 ;{ }^{* *} P<0.001$.

mice, referred to as $r d 1 / r d 1$ Opn $4^{-/-}$mice), 2 mouse models of stationary night blindness, which show minimal or no intrinsic light responses but do not undergo retinal degeneration (Gnat1- ${ }^{-1}$ Gnat $2^{--O} \mathrm{Opn} 4^{-/-}$mice, which lack the G protein transducin $\alpha$ subunits 1 and 2 and melanopsin, and $\mathrm{Tra}^{--} \mathrm{Cnga3}^{--} \mathrm{Opn} 4^{-/-}$mice, which lack transducin $\alpha$, cyclic nucleotide-gated channel $\alpha 3$, and melanopsin) (35-37), and WT retinas under two different conditions (WT in artificial cerebrospinal fluid [ACSF] and WT in presence of NBQX and L-AP4 to block synaptic transmission between photoreceptor cells and bipolar cells). A schematic overview of the experiments is depicted in Figure 6A.

When applied to WT retinas, DAD did not change the amplitude or polarity of the retinal light response (Figure 6, B and C). DAD treatment did not significantly alter the average retinal $O N$ or OFF light response (Table 1 and Figure 6, F and G), and the distribution of individual ON, OFF, and ON/OFF RGC light responses did not change either (Supplemental Figure 11). Since the effect of DAD on inner retinal neurons might be overshadowed by the photoreceptor-mediated light response in the WT retina, we performed a second set of experiments in the presence of the mGluR6 receptor agonist L-AP4 and AMPA/kainate receptor antagonist NBQX, blocking ON and OFF signaling from photoreceptor cells, respectively (38-40). Only a small residual light response could be detected after application of these blockers, which was not enhanced by DAD treatment (Table 1, Figure 6F, and Supplemental Figure 12A). To show that NMDA receptor signaling is sufficient to convey synaptic transmission from bipolar cells to RGCs, we performed the same experiments in the blind TKO mouse after treatment with DAD and detected large light-dependent changes in RGC firing rate on the MEA (PI $=0.51 \pm 0.11, n=5$ retinas) (Supplemental Figure 13).

To evaluate DAD in another mouse model of blindness, we studied its effect on the $r d 1$ mouse retina. As expected, DAD could restore robust light-dependent spiking patterns comparable to those in TKO mice with a similar light-intensity threshold (Table 1, light-intensity threshold $=2 \times 10^{13}$ photons $/ \mathrm{cm}^{2} \mathrm{~s}\left[9 \mu \mathrm{W} / \mathrm{cm}^{2}\right]$, and Figure $6 \mathrm{~F}$ ). In addition, the waveforms of light-dependent RGC firing were qualitatively identical to those seen in TKO mice (data not shown).

DAD was not able to elicit any light responses in nondegenerating retinas ( $\mathrm{Tra}^{-/-} \mathrm{Cnga3}^{--} \mathrm{Opn}^{-{ }^{--}}=1.8$ spikes/s) (Figure 6, F and G, and Supplemental Figure 12C). A small residual light response

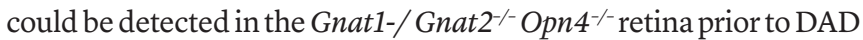
treatment (Figure 6E and Supplemental Figure 12B), most likely due to alternative $G$ protein pathways of the visual cascade in photoreceptor cells (41). However, this light response was at least 2.5fold smaller compared with DAD-induced light responses in TKO retinas and was not increased by application of DAD (light-elicited change in RGC firing rate: Gnat1 ${ }^{-/}$Gnat2 ${ }^{--} \mathrm{Opn} 4^{-/}=18.7$ spikes/s, $\mathrm{TKO}=52.6$ spikes $/ \mathrm{s}, P=0.009$ ) (Table 1 and Figure $6 \mathrm{G}$ ).

Since the photoreceptor degeneration gradually progresses in the TKO retina, we compared the effect of DAD in young versus old TKO mice. Until postnatal week 3, the TKO retina remains morphologically largely intact, even when the mice are born blind, whereas at 6 months, photoreceptor degeneration is complete (22). We compared light responses for two time points (3-weekold and >6-month-old TKO mice). In all cases, young TKO mice had reduced light-dependent spiking rates compared with older TKO mice (photoswitch index in more-than-6-month old mice $\left[\mathrm{PI}_{\text {old }}\right]=0.48 \pm 0.03, n_{\text {old }}=6$; photoswitch index in young mice $\left.\left[\mathrm{PI}_{\text {young }}\right]=0.29 \pm 0.01, n_{\text {young }}=7, P=0.007\right)($ Figure $6, \mathrm{D}, \mathrm{E}$, and $\mathrm{H})$. This further confirms the hypothesis that retinal degeneration is a prerequisite for enabling DAD-mediated retinal photosensitization.

Spatiotemporal properties of the DAD-mediated light response. Visual acuity is highly dependent on the kinetics of the light response. We therefore assessed the minimum light application

Table 1. Average retinal light responses from mouse strains with and without retinal degeneration before and after DAD treatment

\begin{tabular}{|c|c|c|c|c|c|c|c|c|c|}
\hline & \multicolumn{3}{|c|}{ Without DAD } & \multicolumn{3}{|c|}{ With DAD } & & & \\
\hline & PI & SEM & $n$ & PI & SEM & $n$ & $\Delta \mathrm{PI}$ & SEM & $P$ value \\
\hline WT block & 0.046 & 0.060 & 5 & 0.052 & 0.067 & 4 & -0.004 & 0.059 & 0.95 \\
\hline $\mathrm{Rho}^{-/-} \mathrm{Cnga}^{-/-} \mathrm{Opn4^{-/- }}$ & -0.046 & 0.100 & 6 & 0.423 & 0.044 & 6 & 0.435 & 0.095 & 8.77E-05 \\
\hline $\mathrm{Tra}^{-/-} \mathrm{Cnga3}^{-/-} \mathrm{Opn4^{-/- }}$ & -0.003 & 0.007 & 5 & 0.006 & 0.008 & 5 & 0.009 & 0.022 & 0.72 \\
\hline 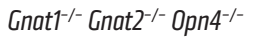 & 0.405 & 0.050 & 6 & 0.366 & 0.047 & 6 & -0.039 & 0.017 & 0.58 \\
\hline
\end{tabular}

Only mouse strains undergoing photoreceptor degeneration show a significant difference in the light response (bold), whereas none of the other retinas respond differently to light in presence of DAD. P values were determined by comparison of the PI values before and after application of DAD using the Wilcoxon rank-sum test 

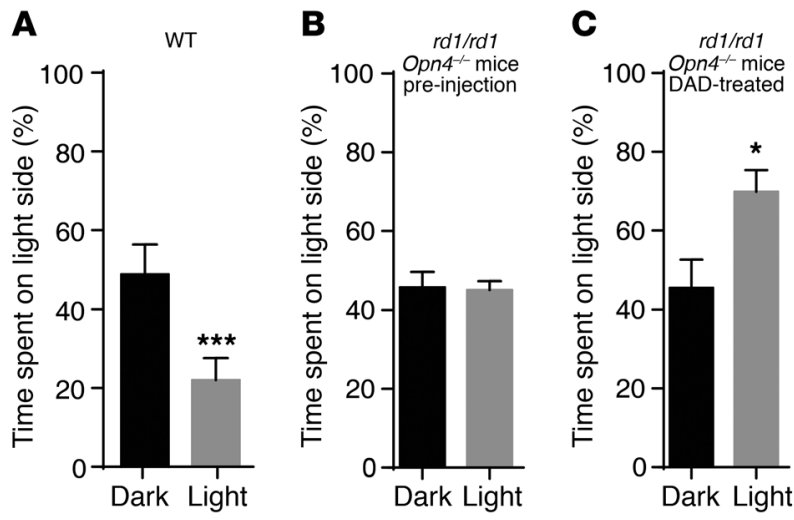

Figure 7. DAD restores light sensitivity to blind mice in vivo. Time spent on the light side of a light-dark shuttle box for (A) WT mice $(n=10, P<0.01)$, (B) $r d 1 / r d 10 p n 4^{-/-}$mice before injection $(n=12)$, and (C) after injection with $7.5 \mathrm{mM}$ DAD $(n=12, P<0.05)$. Light levels used in this experiment were in the range of $4.2 \times 10^{16}$ photons $/ \mathrm{cm}^{2} \mathrm{~s}\left(18 \mathrm{~mW} / \mathrm{cm}^{2}\right)$. Statistical analysis was performed using paired 1-tailed Student's $t$ test. ${ }^{*} P<0.05$; ${ }^{* *} P<0.001$.

able to trigger a significant increase in spiking activity. Under bright light conditions $\left(1.25 \times 10^{16}\right.$ photons $\left./ \mathrm{cm}^{2} \mathrm{~s}, 5.5 \mathrm{~mW} / \mathrm{cm}^{2}\right)$, a short 50 -ms light pulse was sufficient to trigger a significant increase in RGC spiking frequency $(P<0.05, n=8$ retinas) (Supplemental Figure $14 \mathrm{~A})$. The maximum firing rate was achieved with $500-\mathrm{ms}$ to 1,000 -ms light pulses (average $\mathrm{PI}=0.49 \pm 0.03, n=8$ retinas) (Supplemental Figure 14, A and B). When light was switched off after maximal stimulation, the firing rate returned to baseline within approximately $1,000 \mathrm{~ms}$ ( $\tau_{\text {off }}=621.4 \pm 51.3 \mathrm{~ms}$ ) ( $n=8$ retinas).

The minimum light intensity for triggering RGC responses in DAD-treated $r d 1 / r d 1$ retinas was $3 \times 10^{13}$ photons $/ \mathrm{cm}^{2} \mathrm{~s}(13.5 \mu \mathrm{W} /$ $\mathrm{cm}^{2}$ ) (Supplemental Figure 14C), similar to the threshold reported for DENAQ (16) as well as for retinas expressing channelrhodopsin or halorhodopsin $(12,42)$. The light responses of DAD-treated retinas increased over 3 orders of magnitude of brightness, from $10^{13}$ to $10^{16}$ photons $\mathrm{cm}^{-2} \mathrm{~s}^{-1}$, and the half-maximal response was achieved with a light intensity of $1 \times 10^{14}$ photons $\mathrm{cm}^{-2} \mathrm{~s}^{-1}\left(0.045 \mathrm{~mW} / \mathrm{cm}^{2}\right)$.

In order to test whether DAD-treated retinas are able to generate spatially precise light responses, an important feature of any vision restoration approach (43), we set out to characterize the response properties of DAD-treated $r d 1$ retinas to small spot light stimulation. Illumination with a $90-\mu \mathrm{m}$ spot of white light resulted in an increase in activity of the RGCs recorded by the illuminated electrode ( $\mathrm{PI}=0.41 \pm 0.15, n=22$ cells) (Supplemental Figure $15 \mathrm{~A})$. None of the surrounding RGCs responded to the stimulus (PI $=0.00 \pm 0.11, n=1,206$ cells, $P<0.001$ ) (Supplemental Figure 15B). As we stimulated the retina with spots of light of increasing diameter, the RGC light response saturated at a spot size of 240 $\mu \mathrm{m}$, close to the previously reported average dendritic field diameter of mouse RGCs (Supplemental Figure 15C) (44). Stimulation with a $30-\mu \mathrm{m}$ diameter light spot triggered an increase in activity in most illuminated RGCs, suggesting that neighboring RGCs can, in principle, be controlled independently of one another.

$D A D$ restores innate light-dependent behavior in blind mice. We next set out to determine DAD's suitability as a potential therapeutic for restoring visual function. To test this, we first determined the decay time of DAD availability after injection into the vitre- ous cavity of $r d 1 / r d 1$ mice. At several time points after injecting a solution of $5 \mathrm{mM}$ DAD (0.5\% DMSO in buffered salt solution, $2 \mu \mathrm{l})$, mice were sacrificed and the retina was put on a MEA to record RGC activity. Three to six hours after injection, robust light responses were detected $(\mathrm{PI}=0.38 \pm 0.04, n=4$ retinas) (Supplemental Figure 16, A and B). The retinas were light responsive for up to 24 hours (half-life $=8.8$ hours) (Supplemental Figure 16C), i.e., until the vitreous cavity was cleared of DAD. The fast wash out mirrors the high solubility of DAD in physiological buffers as well as in macaque vitreous (Supplemental Figure 16D).

For future in vivo studies, additional solvents (e.g., DMSO) need to be avoided. Therefore, DAD was also formulated as DAD-HCl salt, which was readily soluble in water or buffer (200 $\mathrm{mM})$. The $\mathrm{HCl}$ formulation of DAD was at least as effective as DAD in DMSO after intravitreal injection (Supplemental Figure 16B) and was therefore used for all in vivo experiments and for ex vivo experiments after it was confirmed that there was no difference in activity.

To determine whether $\mathrm{DAD}-\mathrm{HCl}$ is capable of restoring light-dependent visual responses to blind mice, we utilized a lightdark shuttle box (Figure 7) (45). Briefly, mice were placed in a dual chamber enclosure, with one transparent side and one opaque side. The total time spent on each side of the apparatus was measured for a 5-minute-exposure time to either light or darkness (in which case the two sides of the apparatus would both be "dark"). As shown in Figure 7A, WT mice spent $50 \%$ of their time in darkness on each side of the apparatus, but when the apparatus was placed in white light, they spent approximately $80 \%$ of their time on the dark side of the apparatus. When $r d 1 / r d 1 \mathrm{Opn}^{-/-}$(46) animals were placed in the apparatus, they spent $50 \%$ of their time on each side of the apparatus, regardless of whether the apparatus was placed in light or dark conditions (Figure 7B). Two hours after intravitreal injection of $\mathrm{DAD}$, the same mice showed a strong preference $(72 \%)$ for the light side of the box under light treatment, while the preference remained at 50\% when tested under dark conditions (Figure 7C). A similar paradoxical preference for light was also observed in "positive masking" under dim light conditions in melanopsin-deficient mice (47).

\section{Discussion}

Over the past decade, several approaches, including retinal implants, stem cell therapy, and viral gene therapy, have been pursued with the goal of reversing outer retinal blindness and preventing progressive retinal degeneration. Despite their great promise, these approaches share several drawbacks - they are either highly invasive and/or essentially irreversible. Thus, these treatments cannot be readily terminated in case of adverse side effects. Furthermore, it is difficult if not impossible for improved treatments to be delivered to the same cohort of treated patients. Our PCL approach circumvents these challenges by exploiting the advantages of photopharmacology. PCL molecules, such as small-molecule ion channel blockers, can be easily injected into the eye (Supplemental Figure 16) $(18,19)$. In this work, we characterize DAD, a third-generation photoswitch.

When compared with previous PCLs applied to blind retinas (i.e., AAQ and DENAQ), DAD shows three advantageous features. First, DAD preferentially photosensitizes bipolar cells. Second, 
DAD is able to generate more complex output signals from RGCs (i.e., ON-OFF responses). And third, DAD has in increased solubility in water or physiological buffer.

Similar to DENAQ, DAD affects HCN channels in RGCs, but unlike DENAQ, DAD's photosensitizing effect is largely mediated by bipolar cells, thereby utilizing more of the remaining retinal circuitry, i.e., bipolar and amacrine cells. This finding is supported by the fact that light elicited EPSCs recorded from DAD-treated TKO RGCs (Figure 4). We have further demonstrated that DADmediated peak currents are eliminated by application of NBQX and D-AP5. The plateau currents mediated through HCN channels, however, were reduced but not prevented by the excitatory blockers (Supplemental Figure 6). It is therefore conceivable that only the summation of DAD-mediated excitatory synaptic input from bipolar cells and the depolarization of RGCs through HCN channel block combine to generate a sufficiently strong inward current to drive RGC activity. This could also explain the transient and sustained phases of the light response, with the transient peak primarily due to synaptic input and the sustained plateau attributable to the depolarization of RGCs. This hypothesis is consistent with the MEA experiments in which the transient peak response is clearly eliminated by synaptic blockers (NBQX and D-AP5). Nevertheless a few individual RGCs still exhibited light-dependent modulation of activity, especially after a long (>20 minute) DAD incubation (Supplemental Figure 17).

There are three possible pathways for how DAD restores light sensitivity to blind retinas. First, DAD might activate cone bipolar cells, then form synapses on RGCs as well as surrounding amacrine cells (Figure $4 \mathrm{H}$ ). Second, rod bipolar cells could be triggered by DAD to activate AII amacrine cells and then cone ON-RGCs through gap junctions (Figure 4H) (48). Third, small OFF responses could be induced via the rod bipolar and AII amacrine cell pathway on OFF-RGCs via a glycinergic synapse (Figure $4 \mathrm{H})(14,33,49,50)$.

Additional patch-clamp studies in bipolar cells revealed that DAD induces a transient light response, which is insensitive to membrane voltages and a slower second component that is mediated via potassium channels. The reduction of DAD-mediated currents by the application of MFA indicates that the transient current is conveyed through gap junction coupling. However, the molecular target of DAD remains to be determined.

In contrast to all previous PCLs, which were only able to generate light $\mathrm{ON}$ responses in the blind retina $(18,19)$, DAD overcomes this limitation by partially restoring both the ON and OFF retinal light responses (Supplemental Figure 3 and 4; although it should be noted that OFF responses were less frequently observed than $\mathrm{ON}$ in our experiments; the reason for the preferential restoration of the ON pathway is not presently known). This could allow additional spatial and temporal information for further processing and could theoretically lead to better image resolution (i.e., limited by the density of bipolar cells) or potentially allow patients to distinguish moving patterns (51). However, it remains to be determined whether DAD is able to restore high acuity spatial and temporal vision (such as that measured by optokinetic reflex testing in mice). Optogenetic approaches to vision restoration, such as expression of halorhodopsin in remnant cones or expression of ChR2 or the chimeric light-sensitive opto-mGluR6 receptor in ON bipolar cells, are also capable of restoring both $\mathrm{ON}$ and $\mathrm{OFF}$ retinal light responses in $r d 1$ mice $(12,52,53)$. However, the delivery of optogenetic tools requires viral gene therapy, which carries a number of potential safety risks. Furthermore, expression in remaining cones is restricted to the early onset of retinal degeneration, when cone cell bodies are still present. Viral transfection affects not only degenerated areas of the retina, but also healthy parts, which may interfere with normal light responses in still intact areas of the retina.

DAD is highly soluble (up to $200 \mathrm{mM}$ in physiological buffers) as compared with previously described photoswitches. This high solubility of DAD has both positive and negative aspects. On the one hand, it increases access to retinal tissue; on the other hand, it leads to fast wash out after intravitreal injection (Supplemental Figure 16C). Furthermore, because of the high extinction coefficient $(26,772 \mathrm{l} / \mathrm{mol} \mathrm{cm})$ of DAD, it filters a large portion of the useful wavelength light from reaching the retina when applied in high concentrations to the vitreous. However, solubility is often a limiting factor for drug application, and poor solubility often hard to overcome. The high solubility of DAD opens the possibility of sustained drug release using nanoparticles (54-56). Sustained drug release would be advantageous in two respects: (a) the drug would be available in the vitreous for days to weeks after nanoparticle injection and (b) a sustained release method will lead to a reduction in working concentration from $5 \mathrm{mM}$ to $200 \mu \mathrm{M}$ in vivo, which would increase the amount of light reaching the retina through DAD-stained vitreous. Alternatively, subretinal or suprachoroidal DAD delivery may allow for a therapeutic dose to reach the retina while not staining the vitreous or lens.

DAD light sensitivity is comparable to previously reported photoswitches, with a light intensity threshold of $3 \times 10^{13}$ photons/ $\mathrm{cm}^{2} \mathrm{~s}$, which is equal to bright daylight conditions (Supplemental Figure $14 C)(18,19)$. However, the behavioral effect of DAD in vivo is paradoxical: while WT mice prefer dark conditions in a lightdark shuttle box, DAD-treated animals preferred the light side of the box. It has previously been shown that low light levels augment activity in mice (positive masking) (57). This positive masking is replaced by negative masking (i.e., less activity) as the light intensity increases. Negative masking has also been seen in animals with degenerated retinas, i.e., no light sensitivity. Therefore, positive masking has also been used for determining the stage of retinal degeneration, as the same light levels are perceived differently in mice undergoing retinal degeneration when compared with WT mice (58). We hypothesize that the high light absorption by DAD in the vitreous decreases the light levels sufficiently that the mice sense it as low light levels. DAD, however, clearly restores behavioral light sensitivity, and it remains to be investigated whether lower intravitreal concentrations reverse the positive masking. Alternatively, the specific bipolar pathways excited by DAD could induce positive masking as well. Future experiments, including the analysis of the effects of DAD on the intrinsically photosensitive RGCs that mediate masking $(47,59,60)$, will determine the mechanism of the observed paradoxical responses to light.

Like the second-generation photoswitch DENAQ, DAD has no apparent effects on light-induced firing in healthy mouse retinas. In patients undergoing retinal degeneration, large parts of the retina often remain unaffected over a long period of time. For example, in patients with retinitis pigmentosa, peripheral vision is lost first followed by a much slower degeneration in central areas (61). 
Here, it would be preferable to selectively target degenerated parts of the retina and exclude the remaining healthy areas. Application of DAD in early stages of disease is conceivable, as activation in partly degenerated retinas ( $<3$ weeks old) has been demonstrated. Whether multiple or long-term DAD applications have effects on healthy retinal tissue remains to be determined. Toxicological studies, including assessment of the effects of repeated exposure, are an integral part of future investigations in rabbit and dog retinas.

At present, we do not know why DAD only affects degenerating retinas and has no effect on morphologically intact tissue. Studies on previous generation photoswitches have demonstrated that uptake through $\mathrm{P}_{2} \mathrm{X}$ receptors, which are upregulated in retina undergoing degeneration, play a crucial role (25). The same mechanism, however, could be excluded for DAD treatment (Supplemental Figure 8). This result was not surprising, since the biophysical properties of DAD (i.e., not permanently charged) are different from previous VGIC photoswitches. The basis of DAD selectivity for degenerated retina remains unclear. The noncharged fraction of DAD may penetrate the membrane directly, allowing DAD to access all retinal cell types. We have, however, shown that it primarily photosensitizes retinal bipolar cells. The increased excitability of the retinal bipolar-amacrine cell network in retinas undergoing degeneration has been studied extensively $(62,63)$. Small changes in the membrane resting potential of bipolar cells during retinal degeneration have been shown to form oscillations in the AII/ON bipolar cell pathway characteristic of retinas undergoing degeneration $(63,64)$. Other studies, however, have shown that bipolar cells in the $r d 1$ retina remain relatively hyperpolarized (26). ON bipolar cells showed a membrane potential of $-52 \mathrm{mV}$, approximately $7 \mathrm{mV}$ depolarized compared with nondegenerated retinas $(26,65)$. Trenholm et al. on the other hand argue that a decrease in resting cationic conductance through loss of mGluR6-gated channels may lead to an increase in input resistance, which could also affect the ability of photosensitization by DAD (63). However, whether the shifts in membrane potential or an increase in input resistance enables DAD photoactivation of bipolar cells remains to be investigated.

We have also demonstrated that in DAD-treated retinas there is a population of RGCs that exhibit fast light ON responses and is able to follow a temporal $5-\mathrm{Hz}$ light stimulation (Supplemental Figure 4). WT mice have been shown to reliably follow a 5- to -7-Hz light stimulation; only a small subset of RGCs, which receive cone-mediated responses, are able to temporally distinguish 10to $30-\mathrm{Hz}$ light stimulation (66). Behavioral studies in WT mice demonstrated a predominant 2- to $5-\mathrm{Hz}$ light sensitivity (67) Therefore, we conclude that DAD could in principle recover temporal light response similar to those in WT mice.

Taken together, DAD is an improved photoswitch for "retinal reanimation" (68) and potential reversal of outer retinal blindness. In addition to its increased solubility in physiological buffers, DAD targets retinal neurons upstream of RGCs and therefore generates a more complex and more native output signal when compared with previous PCLs. Thus, it restores both ON and OFF light responses in blind retinas. Furthermore, DAD only targets retinas undergoing degeneration; therefore, healthy tissue will likely not be affected, as in genetic approaches. It is likely that a photopharmacological treatment would be less disruptive than current approaches in clinical trials (4). DAD demonstrates that photoswitches, like optogenetic tools, can affect a variety of different cell types in the retina and generate a variety of different light responses. It also provides a template for the development of new cell-type selective photoswitches - an important goal for the restoration of complex visual function.

\section{Methods}

Chemical synthesis. DAD was synthesized as an $\mathrm{HCl}$ salt in accordance with the synthetic route described in the Supplemental Methods. All other chemicals were purchased from Abcam or Tocris Bioscience.

Animals and retina preparation. For MEA recordings, unless noted otherwise, we used 3- to 7-month-old homozygous TKO mice. These completely light-insensitive mice were generated by crossing the $\mathrm{Cnga3}^{-/-} \mathrm{Rho}^{-/-}$double knockout mouse (22) with the Opn $4^{-/-}$mouse provided by Samer Hattar (Johns Hopkins University, Baltimore, Maryland, USA) (69).

To determine whether retinal degeneration is necessary for DAD-mediated reactivation of the retinal circuitry, retinas from 4 different mouse lines were tested besides the TKO retinas: two blind but

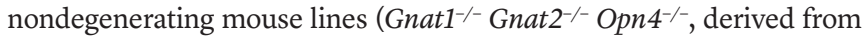

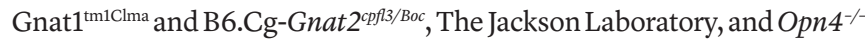
[gift of Satchin Panda, Salk Institute, La Jolla, California, USA]), Tra ${ }^{-/-}$ $\mathrm{Cnga3}^{-/-} \mathrm{Opn} 4^{-/-}$mice (a gift of King-Wai Yau, Johns Hopkins University), and the blind, degenerating mouse line $r d 1 / r d 1 \mathrm{Opn}^{-/-}$.

For behavioral studies, $r d 1 / r d 1$ Opn $4^{-/}$mice $(\mathrm{C} 3 \mathrm{H} / \mathrm{HeJ}$ strain, Charles River Laboratories) were also used. Mice were sacrificed by cervical dislocation. Retinas were dissected; kept in ACSF at room temperature containing $125 \mathrm{mM} \mathrm{NaCl}, 2.5 \mathrm{mM} \mathrm{KCl}, 1.25 \mathrm{mM} \mathrm{NaH}_{2} \mathrm{PO}_{4}, 1$ $\mathrm{mM} \mathrm{MgCl}_{2}, 2 \mathrm{mM} \mathrm{CaCl}_{2}, 26 \mathrm{mM} \mathrm{NaHCO}_{3}$, and $20 \mathrm{mM} \mathrm{D}$-glucose; and aerated with $95 \% \mathrm{O}_{2} / 5 \% \mathrm{CO}_{2}$.

Retinal slice preparations were performed with 3\% low-melting agarose in HEPES Ringer $(\mathrm{pH}=7.4)$. A small Pasteur pipette was used to fill a 35-mm Petri dish with low-melting- point agarose (Invitrogen). Forceps were used to test consistency and after begin of solidification of the agarose the flattened retina was transferred to the top of the agar. Excess solution was removed with a filter paper, and a few drops of melted agar were placed directly on top of the retina. A circular plastic cylinder was placed over the retina to form a wall around it. Then, the cylinder was filled with melted agar, and the Petri dish was placed on an ice water bath to cool. After complete solidification of the agar (approximately 1 minute), the cylinder was removed and the agar containing the retina was extruded. A razor blade was used to cut out a small block of agar containing the retina. The agar block was glued to the specimen disc and filled with ice-cold HR. Slices with a thickness of 400-450 $\mu \mathrm{m}$ were cut using a Campden vibratome $7000 \mathrm{smz}-2$ (NPI Electronic) and directly transferred to the recording chamber. The slice anchor was mounted to hold down the surrounding agar, while the retina was unobstructed for recordings.

MEA electrophysiology. For extracellular recordings, a flat-mounted retina was placed ganglion cell layer down onto an MEA chip (200/30 ITO, Multichannel Systems) and recorded on a MEA 1060-inv-BC system (Multi-Channel Systems). Retinas were pretreated with $200 \mu \mathrm{M}$ DAD for 3 minutes, followed by a 15- to 25-minute wash with ACSF. Extracellular spikes were high-pass filtered at $300 \mathrm{~Hz}$ and digitized at $20 \mathrm{kHz}$. A spike threshold of 4 SD was set for each channel. Typically, each electrode recorded spikes from 1 to 3 RGCs. Analysis of spike 
waveforms was performed using the principle component analysis of spike waveforms using Plexon Offline Sorter (version 3).

Patch-clamp electrophysiology. Whole-cell patch-clamp recordings in cortical layer $2 / 3$ neurons were performed in acute coronal slice preparations from WT mice (postnatal day 10-15). Slice preparation was performed under the same conditions as previously described (17).

Prior to recording, slices were incubated with $200 \mu \mathrm{M}$ DAD in ACSF solution for 3 minutes at room temperature. Recordings were performed at room temperature. Cells were patched using borosilicate glass electrodes (Science Products) with resistances between 6 and $9 \mathrm{M} \Omega$. Intracellular solution for voltage clamp recordings in cortical neurons consisted of $140 \mathrm{mM}$ K-gluconate, $10 \mathrm{mM}$ HEPES, $12 \mathrm{mM}$ $\mathrm{KCl}, 4 \mathrm{mM} \mathrm{NaCl}, 4 \mathrm{mM}$ Mg-ATP, $0.4 \mathrm{mM}$ Na-GTP, pH 7.3, with $\mathrm{KOH}$ (ca. $300 \mathrm{mOsm}$ ). Currents were recorded at a holding potential of -60 $\mathrm{mV}$, and $1 \mu \mathrm{M}$ TTX was added to the extracellular solution. To evaluate the kinetics of blocking/unblocking $\mathrm{K}_{\mathrm{v}}$ channels light dependently, cells were depolarized from a holding potential of $-60 \mathrm{mV}$ to $+50 \mathrm{mV}$. During the depolarization, pulse DAD was switched from trans (dark) to cis $(460 \mathrm{~nm})$ and back. Light-induced currents were corrected for desensitization, and $t$ was calculated from this DAD-mediated current trace. For on cell recordings from RGCs and identification of excitatory and inhibitory inputs onto RGCs, patch-clamp experiments were performed in TKO retina in whole-mount configuration. Retinas were treated with $200 \mu \mathrm{M}$ DAD, as in MEA experiments. For wholecell recordings electrodes were pulled with 4 to $6 \mathrm{M} \Omega$ resistance and filled with $120 \mathrm{mM}$ Cs-methansulfonate, $5 \mathrm{mM}$ TEA, $10 \mathrm{mM}$ HEPES, $3 \mathrm{mM} \mathrm{NaCl}, 10 \mathrm{mM}$ EGTA, 2 mM QX-314, 2 mM Mg-ATG, $0.3 \mathrm{mM}$ Na-GTP, and 1\% Lucifer Yellow (Sigma Aldrich) in order to visualize the neurons during the recording. The $\mathrm{pH}$ was adjusted to 7.3 with $\mathrm{CsOH}$. Excitatory inputs were recorded at a holding potential of -60 $\mathrm{mV}$, and inhibitory currents were recorded at $0 \mathrm{mV}$. Holding potentials were corrected as described previously (70).

For investigation of DAD-mediated currents through HCN channels, we used TKO retinas in whole-mount preparation and performed patch-clamp experiments with an intracellular solution containing $140 \mathrm{mM}$ K-gluconate, $10 \mathrm{mM}$ HEPES, $12 \mathrm{mM} \mathrm{KCl}, 4 \mathrm{mM} \mathrm{NaCl}, 4 \mathrm{mM}$ Mg-ATP, and $0.4 \mathrm{mM} \mathrm{Na}_{2}$-GTP. For on cell recordings, electrodes with resistances between 3 and $5 \mathrm{M} \Omega$ were pulled and filled with extracellular solution. Recordings in whole-mount retinas were performed at $34^{\circ} \mathrm{C}$.

For bipolar cell patch-clamp experiments, retinal slices were incubated with $200 \mu \mathrm{M}$ DAD-HCl for 3 minutes. Electrodes were pulled with 12-14 $\mathrm{M} \Omega$ resistance and filled with intracellular solution containing 140 mM K-gluconate, 10 mM HEPES, $12 \mathrm{mM} \mathrm{KCl,} 4 \mathrm{mM} \mathrm{NaCl}$, 4 mM Mg-ATP, 0.4 mM Na-GTP, and1\% Lucifer Yellow, pH 7.3, with $\mathrm{KOH}$ or $120 \mathrm{mM}$ Cs-methansulfonate, $5 \mathrm{mM}$ TEA, $10 \mathrm{mM}$ HEPES, $3 \mathrm{mM} \mathrm{NaCl}, 10 \mathrm{mM}$ EGTA, $2 \mathrm{mM}$ QX-314, 2 mM Mg-ATG, $0.3 \mathrm{mM}$ Na-GTP, and 1\% Lucifer Yellow.

Recordings were performed with the EPC 10 USB amplifier controlled by Patchmaster software (HEKA). Acquisition rate was $50 \mathrm{kHz}$, and data were filtered at $2.9-10 \mathrm{kHz}$. Holding potentials were corrected for their liquid junction potentials. Cortical neurons with leak currents $>200 \mathrm{pA}$ or series resistances of $>25 \mathrm{M} \Omega$, RGC patch-clamp recordings with $>250 \mathrm{pA}$ or series resistances of $>25 \mathrm{M} \Omega$, and bipolar cell recordings with $>50 \mathrm{pA}$ and $>25 \mathrm{M} \Omega$ were excluded from analysis.

Light stimulation. MEA recordings were performed with a MCS software-controlled 460-nm LED lamp (UHP-Mic-LED-460,
Prizmatix) with a light intensity of $3.1 \times 10^{16}$ photons $/ \mathrm{cm}^{2} \mathrm{~s}(13.5 \mathrm{~mW} /$ $\mathrm{cm}^{2}$ ) unless stated otherwise.

For white light recordings, a xenon light source (Sutter Instruments) fed through a liquid light guide and diffusing filter (Thorlabs Inc.) was used. Intensities and wavelengths of light were adjusted via neutral density filters (Thorlabs Inc.) and calibrated with a radiometer (Advanced Photonics International). Light stimuli were delivered and monitored by a computer-controlled shutter (Vincent Associates).

To compare light sensitivity of DAD to DENAQ, those experiments were performed under the same conditions as previously published (16). The photon flux equivalent for DAD-treated retinas was calculated using $450 \mathrm{~nm}$ (photoswitch absorbance peak) photon energy. The incident white light intensity for $r d 1 / r d 1$ retinas was $1.5 \times$ $10^{15}$ photons $/ \mathrm{cm}^{2} \mathrm{~s}\left(0.65 \mathrm{~mW} / \mathrm{cm}^{2}\right)$ and $1.4 \times 10^{14}$ photons $/ \mathrm{cm}^{2} \mathrm{~s}(0.06$ $\mathrm{mW} / \mathrm{cm}^{2}$ ) for $\mathrm{Tra}^{-/-} \mathrm{Cnga3}^{-/-} \mathrm{Opn}^{-/-}$retinas, unless stated otherwise. A typical MEA stimulation protocol consisted of 10 cycles of alternating 15-second light/dark intervals. The same protocol was applied for analysis of single spot illumination and after intravitreal injections. For patch-clamp recordings in whole-mount retina preparations the UHPMic-LED-460 (Prizmatix) $(460 \mathrm{~nm}$ ) was connected to the microscope. The action spectrum of DAD was determined in brain slice whole-cell patch-clamp recordings using a Polychrome V (Till Photonics).

Pharmacology. In order to block excitatory input on RGCs, 25 $\mu \mathrm{M}$ NBQX and $50 \mu \mathrm{M}$ D-AP5 were perfused. Inhibitory currents were blocked using a cocktail of $1 \mu \mathrm{M}$ strychnine, $5 \mu \mathrm{M}$ picrotoxine, and $10 \mu \mathrm{M}$ (1,2,5,6-tetrahydropyridin-4-yl)methylphosphinic acid $(18,19)$. RGC isolation was achieved with a combination of above-mentioned blockers for excitatory and inhibitory input or by application of $500 \mu \mathrm{M} \mathrm{CdCl}$. To block photoreceptor inputs onto bipolar cells in WT retinas, we applied $10 \mu \mathrm{M} \mathrm{L}-\mathrm{AP} 4$ and 25 $\mu \mathrm{M}$ NBQX, respectively.

Data analysis. For MEA recordings, we calculated the peak RGC firing rate in 100-ms bins for individual retinas in light and in darkness. In order to normalize light-elicited changes in firing rate of individual RGCs in retinas, we calculated the PI as previously described $(18,19)$ : PI = (firing rate in the light - firing rate in darkness)/(firing rate in the light + firing rate in darkness). The first second of dark and light intervals was used to measure the peakfiring rate. Data analysis was performed using custom routines within the IgorPro software (Wavemetrics) or Matlab. Correlation of RGC spiking was analyzed using a 1-second binning prior illumination and the 1 second at the beginning of illumination. A PI of 0.1 was set as minimal threshold for detection.

Intravitreal injections. Before injection, animals were anesthetized with isofluorane (2\%) and their pupils were dilated with tropicamide (1\%). An incision was made through the sclera, below the ora serrata with a 30-gauge needle, and DAD or DAD-HCl (5 mM DAD in PBS, if not otherwise indicated) was injected into the vitreous with a blunt-ended 32-gauge Hamilton syringe.

UV-Vis spectra. $50 \mu \mathrm{M} \mathrm{DAD}$ was dissolved in buffer containing $138 \mathrm{mM} \mathrm{NaCl}, 1.5 \mathrm{mM} \mathrm{KCl}, 2.5 \mathrm{mM} \mathrm{CaCl}_{2}, 1.5 \mathrm{mM} \mathrm{MgCl}_{2}, 10 \mathrm{mM}$ glucose, and $5 \mathrm{mM}$ HEPES. The $\mathrm{pH}$ has been adjusted to 7.3 with $\mathrm{NaOH}$. Samples were recorded in a $100 \mu$ l cuvette with light introduced via a glass fiber coupled to an UHP-Mic-LED-460 (Prizmatix). The glass fiber was arranged perpendicular to the light path of the spectrometer (Varian Cary 50). 
The extinction coefficient was determined by measuring absorption of $0.5,1,5,10$, and $50 \mu \mathrm{M}$ DAD, while illuminating with $460-\mathrm{nm}$ light. The extinction coefficients for all concentrations were calculated using Lambert-Beer's law and averaged. The linear fit of the absorption versus DAD concentration was used to determine the accuracy of the measurements.

Statistics. Statistical significance ( $P$ values) was calculated using the signed Wilcoxon rank-sum test for paired data and the nonsigned Wilcoxon rank-sum test for unpaired data, unless stated otherwise. Results were considered significant at $P<0.05$. Error bars are presented as mean \pm SEM of the mean unless otherwise indicated.

Study approval. All animal use procedures were approved by the University of California, Berkeley, and/or the University of Washington Institutional Animal Care and Use Committees.

\section{Author contributions}

IT performed MEA experiments in Figures 6, F and G; Supplemental Figure 3B; Supplemental Figure 12C; Supplemental Figure 14C; Supplemental Figure 15; and Supplemental Figure 16C. LL performed MEA experiments in all other figures and created all the figures. LL and MBM performed patch-clamp experiments in RGCs. LL performed patch-clamp experiments in retinal bipolar cells. KK and LL performed behavioral experiments. MS and DMB synthesized DAD. CS, SM, and MB generated and provided the TKO mouse line. RNVG supervised the behavioral and MEA experiments. LL and MPS designed the experiments. RHK supervised the experiments performed by IT. LL, IT, DT, and RNVG wrote the paper. DT supervised the project.

\section{Acknowledgments}

We acknowledge James Kuchenbecker for help with light stimulation protocols during the in vivo testing. We thank Jay and Maureen Neitz for their help with the intravitreal injections and Toni Haun for providing us with macaque vitreous. We thank Angela Sandt for construction of the light-dark shuttle box and assistance with animal experiments. The authors thank Samer Hattar (Johns Hopkins University) and Peter Humphries (Trinity College, Dublin) for providing the $\mathrm{Opn}^{-{ }^{--}}$and the $\mathrm{Rho}^{-/-}$mouse lines, respectively. LL thanks the Boehringer Ingelheim Foundation for the support in the form of an international travel grant. We acknowledge the European Research Council (ERC advanced grant 268795 to DT) for financial support. DMB is grateful to the European Commission for a Marie Skłodowska-Curie Intra-European Fellowship (PIEF-GA-2013-627990). RNVG, RHK, and KK were supported by NIH grants R24EY023937 and PN2EY018421. RNVG and KK were supported by NIH grant P3OEY001730; an unrestricted grant from Research to Prevent Blindness; and the Mark J. Daily, MD Research Fund

Address correspondence to: Russell N. Van Gelder, University of Washington School of Medicine, Box 359608, 325 Ninth Ave., Seattle, Washington 98104, USA. Phone: 206.543.7250; Email: russvg@uw.edu. Or to: Dirk Trauner, Department of Chemistry, New York University, Silver Center, 100 Washington Square East, Room 712, New York, New York 10003, USA. Phone: 212.998.3747; Email: dirktrauner@nyu.edu.

LL's present address is: Institute for Synaptic Physiology, Center for Molecular Neurobiology (ZMNH), Hamburg, Germany.
1. Marc R, Pfeiffer R, Jones B. Retinal prosthetics, optogenetics, and chemical photoswitches. ACS Chem Neurosci. 2014;5(10):895-901.

2. Marc RE, Jones BW, Watt CB, Vazquez-Chona F, Vaughan DK, Organisciak DT. Extreme retinal remodeling triggered by light damage: implications for age related macular degeneration. $\mathrm{Mol}$ Vis. 2008;14:782-806.

3. Weiland JD, Cho AK, Humayun MS. Retinal prostheses: current clinical results and future needs. Ophthalmology. 2011;118(11):2227-2237.

4. Chuang AT, Margo CE, Greenberg PB. Retinal implants: a systematic review. Br JOphthalmol. 2014;98(7):852-856.

5. Lorach $\mathrm{H}$, et al. Photovoltaic restoration of sight with high visual acuity. Nat Med. 2015;21(5):476-482.

6. Mandai M, et al. iPSC-derived retina transplants improve vision in rd1 end-stage retinal-degeneration mice. Stem Cell Reports. 2017;8(1):69-83.

7. Shirai H, et al. Transplantation of human embryonic stem cell-derived retinal tissue in two primate models of retinal degeneration. Proc Natl Acad Sci U S A. 2016;113(1):E81-E90.

8. Li Z, et al. Neural stem cells transplanted to the subretinal space of rd1 mice delay retinal degeneration by suppressing microglia activation. Cytotherapy. 2016;18(6):771-784.

9. den Hollander AI, Black A, Bennett J, Cremers FP. Lighting a candle in the dark: advances in genetics and gene therapy of recessive retinal dystro- phies. JClin Invest. 2010;120(9):3042-3053.

10. Schwartz SD, et al. Embryonic stem cell trials for macular degeneration: a preliminary report. Lan cet. 2012;379(9817):713-720.

11. Redmond TM, et al. Rpe65 is necessary for production of 11-cis-vitamin A in the retinal visual cycle. Nat Genet. 1998;20(4):344-351.

12. Busskamp V, et al. Genetic reactivation of cone photoreceptors restores visual responses in retinitis pigmentosa. Science. 2010;329(5990):413-417.

13. Caporale N, et al. LiGluR restores visual responses in rodent models of inherited blindness. $\mathrm{Mol}$ Ther. 2011;19(7):1212-1219.

14. Gaub BM, et al. Restoration of visual function by expression of a light-gated mammalian ion channel in retinal ganglion cells or ON-bipolar cells. Proc Natl Acad Sci U S A. 2014;111(51):E5574-E5583.

15. Fehrentz T, Schönberger M, Trauner D. Optochemical genetics. Angew Chem Int Ed Engl. 2011;50(51):12156-12182.

16. Fortin DL, et al. Photochemical control of endogenous ion channels and cellular excitability. Nat Methods. 2008;5(4):331-338.

17. Stawski P, Sumser M, Trauner D. A photochromic agonist of AMPA receptors. Angew Chem Int Ed Engl. 2012;51(23):5748-5751.

18. Polosukhina A, et al. Photochemical restoration of visual responses in blind mice. Neuron. 2012;75(2):271-282.
19. Tochitsky I, et al. Restoring visual function to blind mice with a photoswitch that exploits electrophysiological remodeling of retinal ganglion cells. Neuron. 2014;81(4):800-813.

20. Laprell L, et al. Restoring light sensitivity in blind retinae using a photochromic AMPA receptor agonist. ACS Chem Neurosci. 2016;7(1):15-20.

21. Mourot A, Tochitsky I, Kramer RH. Light at the end of the channel: optical manipulation of intrinsic neuronal excitability with chemical photoswitches. Front Mol Neurosci. 2013;6:5.

22. Claes E, Seeliger M, Michalakis S, Biel M, Humphries P, Haverkamp S. Morphological characterization of the retina of the CNGA3 (-/-)Rho(-/-) mutant mouse lacking functional cones and rods. Invest Ophthalmol Vis Sci. 2004;45(6):2039-2048.

23. Chang B, Hawes NL, Hurd RE, Davisson MT, Nusinowitz S, Heckenlively JR. Retinal degeneration mutants in the mouse. Vision Res. 2002;42(4):517-525.

24. Postea O, Biel M. Exploring HCN channels as novel drug targets. Nat Rev Drug Discov. 2011;10(12):903-914.

25. Tochitsky I, et al. How azobenzene photoswitches restore visual responses to the blind retina. Neuron. 2016;92(1):100-113.

26. Borowska J, Trenholm S, Awatramani GB. An intrinsic neural oscillator in the degenerating mouse retina. J Neurosci. 2011;31(13):5000-5012. 27. Berntson A, Taylor WR. Response character- 
istics and receptive field widths of on-bipolar cells in the mouse retina. J Physiol (Lond). 2000;524 Pt 3:879-889.

28. Morgans CW, et al. TRPM1 is required for the depolarizing light response in retinal ON-bipolar cells. Proc Natl Acad Sci U S A. 2009;106(45):19174-19178.

29. Hille B. Ion Channels of Excitable Membranes. Sunderland, MA: Sinauer Associates; 2001.

30. Olumi AF. Commentary on "identification of 23 new prostate cancer susceptibility loci using the iCOGS custom genotyping array." Eeles RA, Olama AA, Benlloch S, Saunders EJ, Leongamornlert DA, Tymrakiewicz M, Ghoussaini M, Luccarini C, Dennis J, Jugurnauth-Little S, Dadaev T, Neal DE, Hamdy FC, Donovan JL, Muir K, Giles GG, Severi G, Wiklund F, Gronberg H, Haiman CA, Schumacher F, Henderson BE, Le Marchand L, Lindstrom S, Kraft P, Hunter DJ, Gapstur S, Chanock SJ, Berndt SI, Albanes D, Andriole G, Schleutker J, Weischer M, Canzian F, Riboli E, Key TJ, Travis RC, Campa D, Ingles SA, John EM, Hayes RB, Pharoah PD, Pashayan N, Khaw KT, Stanford JL, Ostrander EA, Signorello LB, Thibodeau SN, Schaid D, Maier C, Vogel W, Kibel AS, Cybulski C, Lubinski J, CannonAlbright L, Brenner H, Park JY, Kaneva R, Batra J, Spurdle AB, Clements JA, Teixeira MR, Dicks E, Lee A, Dunning AM, Baynes C, Conroy D, Maranian MJ, Ahmed S, Govindasami K, Guy M, Wilkinson RA, Sawyer EJ, Morgan A, Dearnaley DP, Horwich A, Huddart RA, Khoo VS, Parker CC, Van As NJ, Woodhouse CJ, Thompson A, Dudderidge T, Ogden C, Cooper CS, Lophatananon A, Cox A, Southey MC, Hopper JL, English DR, Aly M, Adolfsson J, Xu J, Zheng SL, Yeager M, Kaaks R, Diver WR, Gaudet MM, Stern MC, Corral R, Joshi AD, Shahabi A, Wahlfors T, Tammela TL, Auvinen A, Virtamo J, Klarskov P, Nordestgaard BG, Røder MA, Nielsen SF, Bojesen SE, Siddiq A, Fitzgerald LM, Kolb S, Kwon EM, Karyadi DM, Blot WJ, Zheng W, Cai Q, McDonnell SK, Rinckleb AE, Drake B, Colditz G, Wokolorczyk D, Stephenson RA, Teerlink C, Muller H, Rothenbacher D, Sellers TA, Lin HY, Slavov C, Mitev V, Lose F, Srinivasan S, Maia S, Paulo P, Lange E, Cooney KA, Antoniou AC, Vincent D, Bacot F, Tessier DC; COGS-Cancer Research UK GWAS-ELLIPSE (part of GAMEON) Initiative; Australian Prostate Cancer Bioresource; UK Genetic Prostate Cancer Study Collaborators/British Association of Urological Surgeons' Section of Oncology; UK ProtecT (Prostate testing for cancer and Treatment) Study. Urol Oncol. 2014;32(2):211.

31. Kolb H, Famiglietti EV. Rod and cone pathways in the inner plexiform layer of cat retina. Science. 1974;186(4158):47-49.

32. Strettoi E, Raviola E, Dacheux RF. Synaptic connections of the narrow-field, bistratified rod amacrine cell (AII) in the rabbit retina. J Comp Neurol. 1992;325(2):152-168.

33. Manookin MB, Beaudoin DL, Ernst ZR, Flagel LJ, Demb JB. Disinhibition combines with excitation to extend the operating range of the OFF visual pathway in daylight. J Neurosci. 2008;28(16):4136-4150.
34. Jones BW, Kondo M, Terasaki H, Lin Y, McCall M, Marc RE. Retinal remodeling. Jpn JOphthalmol. 2012;56(4):289-306.

35. Chang B, et al. Cone photoreceptor function loss-3, a novel mouse model of achromatopsia due to a mutation in Gnat2. Invest Ophthalmol Vis Sci. 2006;47(11):5017-5021.

36. Lyubarsky AL, Lem J, Chen J, Falsini B, Iannaccone A, Pugh EN. Functionally rodless mice: transgenic models for the investigation of cone function in retinal disease and therapy. Vision Res. 2002;42(4):401-415.

37. Panda S, et al. Melanopsin (Opn4) requirement for normal light-induced circadian phase shifting. Science. 2002;298(5601):2213-2216.

38. Slaughter MM, Miller RF. 2-amino-4phosphonobutyric acid: a new pharmacological tool for retina research. Science. 1981;211(4478):182-185.

39. DeVries SH, Schwartz EA. Kainate receptors mediate synaptic transmission between cones and 'Off' bipolar cells in a mammalian retina. Nature. 1999;397(6715):157-160.

40. DeVries SH. Bipolar cells use kainate and AMPA receptors to filter visual information into separate channels. Neuron. 2000;28(3):847-856.

41. Allen AE, Cameron MA, Brown TM, Vugler AA, Lucas RJ. Visual responses in mice lacking critical components of all known retinal phototransduction cascades. PLoS One. 2010;5(11):e15063.

42. Pan ZH, Ganjawala TH, Lu Q, Ivanova E, Zhang Z. ChR2 mutants at L132 and T159 with improved operational light sensitivity for vision restoration. PLoS One. 2014;9(6):e98924.

43. Reutsky-Gefen I, et al. Holographic optogenetic stimulation of patterned neuronal activity for vision restoration. Nat Commun. 2013;4:1509.

44. Ren L, Liang H, Diao L, He S. Changing dendritic field size of mouse retinal ganglion cells in early postnatal development. Dev Neurobiol. 2010;70(6):397-407.

45. Thiels E, Hoffman EK, Gorin MB. A reliable behavioral assay for the assessment of sustained photophobia in mice. Curr Eye Res. 2008;33(5):483-491.

46. Panda S, et al. Melanopsin is required for nonimage-forming photic responses in blind mice. Science. 2003;301(5632):525-527.

47. Mrosovsky N, Hattar S. Impaired masking responses to light in melanopsin-knockout mice. Chronobiol Int. 2003;20(6):989-999.

48. Demb JB, Singer JH. Intrinsic properties and functional circuitry of the AII amacrine cell. Vis Neurosci. 2012;29(1):51-60.

49. Murphy GJ, Rieke F. Signals and noise in an inhibitory interneuron diverge to control activity in nearby retinal ganglion cells. Nat Neurosci. 2008;11(3):318-326.

50. Cehajic-Kapetanovic J, et al. Restoration of vision with ectopic expression of human rod opsin. Curr Biol. 2015;25(16):2111-2122.

51. Im M, Fried SI. Indirect activation elicits strong correlations between light and electrical responses in ON but not OFF retinal ganglion cells JPhysiol (Lond). 2015;593(16):3577-3596.

52. Macé E, et al. Targeting channelrhodopsin-2 to ON-bipolar cells with vitreally administered AAV Restores ON and OFF visual responses in blind mice. Mol Ther. 2015;23(1):7-16

53. van Wyk M, Pielecka-Fortuna J, Löwel S, Kleinlogel S. Restoring the ON switch in blind retinas: opto-mglur6, a next-generation, cell-tailored optogenetic tool. PLoS Biol. 2015;13(5):e1002143.

54. Rowe-Rendleman CL, et al. Drug and gene delivery to the back of the eye: from bench to bedside. Invest Ophthalmol Vis Sci. 2014;55(4):2714-2730.

55. London NJ, Chiang A, Haller JA. The dexamethasone drug delivery system: indications and evidence. Adv Ther. 2011;28(5):351-366.

56. Groynom R, Shoffstall E, Wu LS, Kramer RH, Lavik EB. Controlled release of photoswitch drugs by degradable polymer microspheres. J Drug Target. 2015;23(7-8):710-715.

57. Mrosovsky N, Foster RG, Salmon PA. Thresholds for masking responses to light in three strains of retinally degenerate mice. J Comp Physiol A. 1999;184(4):423-428

58. Mrosovsky N, Thompson S. Negative and positive masking responses to light in retinal degenerate slow (rds/rds) mice during aging. Vision Res. 2008;48(10):1270-1273.

59. Purrier N, Engeland WC, Kofuji P. Mice deficient of glutamatergic signaling from intrinsically photosensitive retinal ganglion cells exhibit abnormal circadian photoentrainment. PLOS One. 2014;9(10):e111449.

60. Doyle SE, Yoshikawa T, Hillson H, Menaker M. Retinal pathways influence temporal niche. Proc Natl Acad Sci U S A. 2008;105(35):13133-13138.

61. Chen M, Wang K, Lin B. Development and degeneration of cone bipolar cells are independent of cone photoreceptors in a mouse model of retinitis pigmentosa. PLoS One. 2012;7(8):e44036.

62. Choi H, et al. Intrinsic bursting of AII amacrine cells underlies oscillations in the rd1 mouse retina. J Neurophysiol. 2014;112(6):1491-1504.

63. Trenholm S, et al. Intrinsic oscillatory activity arising within the electrically coupled AII amacrineON cone bipolar cell network is driven by voltage-gated $\mathrm{Na}+$ channels. JPhysiol (Lond). 2012;590(10):2501-2517.

64. Menzler J, Channappa L, Zeck G. Rhythmic ganglion cell activity in bleached and blind adult mouse retinas. PLoS One. 2014;9(8):e106047.

65. Ichinose T, Fyk-Kolodziej B, Cohn J. Roles of ON cone bipolar cell subtypes in temporal coding in the mouse retina. J Neurosci. 2014;34(26):8761-8771.

66. Wang YV, Weick M, Demb JB. Spectral and temporal sensitivity of cone-mediated responses in mouse retinal ganglion cells. J Neurosci. 2011;31(21):7670-7681.

67. Umino Y, Solessio E, Barlow RB. Speed, spatial, and temporal tuning of rod and cone vision in mouse. J Neurosci. 2008;28(1):189-198.

68. Van Gelder RN. Photochemical approaches to vision restoration. Vision Res. 2015;111(Pt B):134-141.

69. Hattar S, Liao HW, Takao M, Berson DM, Yau KW. Melanopsin-containing retinal ganglion cells: architecture, projections, and intrinsic photosensitivity. Science. 2002;295(5557):1065-1070.

70. Manookin MB, Weick M, Stafford BK, Demb JB. NMDA receptor contributions to visual contrast coding. Neuron. 2010;67(2):280-293. 